\title{
Identification of selection signatures involved in performance traits in a paternal broiler line
}

Octávio Augusto Costa Almeida', Gabriel Costa Monteiro Moreira', Fernanda Marcondes Rezende², Clarissa Boschiero ${ }^{3}$, Jane de Oliveira Peixoto ${ }^{4}$, Adriana Mercia Guaratini Ibelli ${ }^{4}$, Mônica Corrêa Ledur ${ }^{4}$, Francisco José de Novais ${ }^{1}$ and Luiz Lehmann Coutinho ${ }^{1 *}$ (D)

\begin{abstract}
Background: Natural and artificial selection leads to changes in certain regions of the genome resulting in selection signatures that can reveal genes associated with the selected traits. Selection signatures may be identified using different methodologies, of which some are based on detecting contiguous sequences of homozygous identical-bydescent haplotypes, called runs of homozygosity $(\mathrm{ROH})$, or estimating fixation index ( $\left.\mathrm{F}_{\mathrm{ST}}\right)$ of genomic windows that indicates genetic differentiation. This study aimed to identify selection signatures in a paternal broiler $\Pi$ line at generations 7th and 16th of selection and to investigate the genes annotated in these regions as well as the biological pathways involved. For such purpose, $\mathrm{ROH}$ and $\mathrm{F}_{\mathrm{ST}}$-based analysis were performed using whole genome sequence of twenty-eight chickens from two different generations.

Results: $\mathrm{ROH}$ analysis identified homozygous regions of short and moderate size. Analysis of $\mathrm{ROH}$ patterns revealed regions commonly shared among animals and changes in $\mathrm{ROH}$ abundance and size between the two generations. Results also suggest that whole genome sequencing (WGS) outperforms SNPchip data avoiding overestimation of ROH size and underestimation of ROH number; however, sequencing costs can limited the number of animals analyzed. F ST $^{-}$ based analysis revealed genetic differentiation in several genomic windows. Annotation of the consensus regions of $\mathrm{ROH}$ and $\mathrm{F}_{\text {ST }}$ windows revealed new and previously identified genes associated with traits of economic interest, such as APOB, IGF1, IGFBP2, POMC, PPARG, and ZNF423. Over-representation analysis of the genes resulted in biological terms of skeletal muscle, matrilin proteins, adipose tissue, hyperglycemia, diabetes, Salmonella infections and tyrosine.

Conclusions: Identification of ROH and $\mathrm{F}_{S T}$-based analyses revealed selection signatures in $\Pi$ line and genes that have important role in traits of economic interest. Changes in the genome of the chickens were observed between the 7th and 16th generations showing that ancient and recent selection in $\pi$ line may have acted over genomic regions affecting diseases and performance traits.
\end{abstract}

Keywords: Runs of homozygosity, Fixation index, F $F_{S T}$, Artificial selection, Gallus gallus

\footnotetext{
* Correspondence: Ilcoutinho@usp.br

'University of São Paulo (USP) / Luiz de Queiroz College of Agriculture

(ESALQ), Piracicaba, São Paulo, Brazil

Full list of author information is available at the end of the article
}

(c) The Author(s). 2019 Open Access This article is distributed under the terms of the Creative Commons Attribution 4.0 International License (http://creativecommons.org/licenses/by/4.0/), which permits unrestricted use, distribution, and reproduction in any medium, provided you give appropriate credit to the original author(s) and the source, provide a link to the Creative Commons license, and indicate if changes were made. The Creative Commons Public Domain Dedication waiver (http://creativecommons.org/publicdomain/zero/1.0/) applies to the data made available in this article, unless otherwise stated. 


\section{Background}

Artificial selection of animals lead to changes on particular genomic regions that affect traits of economic interest, as well as traits involved in adaptation to climatic and stress conditions, immune response, and disease resistance [1]. Thus, selection signature regions are printed along the genome as a result of selection pressure. Detecting selection signatures is important for a better understanding of population history and genetic mechanisms affecting phenotypic differentiation in humans, livestock and wild animals [2]. Understanding how selection acts on livestock populations may also benefit breeding programs in order to improve traits of economic interest in these animals, such as chicken breeds which have been intensively selected for fast growth and muscle development [3]. Detection approaches rely on scanning the genome for regions of homozygosity, as well as on estimating allele or haplotype frequency differences between populations or generations within a population. There are several statistical methods for these analyses, such as extended haplotype homozygosity (EHH) [4], integrated haplotype score (iHS) [5], runs of homozygosity $(\mathrm{ROH})[2]$, and $\mathrm{F}_{\mathrm{ST}}$ statistics [6].

Runs of homozygosity are regions in the genome containing contiguous homozygous genotypes identical by descent (IBD), i.e. regions where the pairs of alleles are most likely inherited from a common ancestor [2]. Recent studies used this approach to better understand human diseases [7-9], human ancestry [10], and population structure and traits of interest in livestock species, such as cattle [11-14], swine [15], poultry [16, 17], and sheep [18]. The fixation index $\left(\mathrm{F}_{\mathrm{ST}}\right)$, first defined by Wright [19], is a measure that exploits differences in allele frequencies to infer the genetic differentiation between populations or generations [20]. A certain locus under selection pressure changes its frequency over the generations. Thus, high values of $\mathrm{F}_{\mathrm{ST}}$ indicate candidate selection signatures due to differences in locus frequency among populations or across generations. Previous studies have reported important selection signatures in Virginia [21] and Brazilian broiler and layer chicken lines [22] using this method.

Embrapa Swine and Poultry, a Brazilian National Research Center, has been raising experimental chicken populations under selection since the 1970's. One of these lines is the paternal broiler line called TT, which has been under multi-trait selection since 1992 [23]. Identification of selection signatures in chicken lines can help understand which regions underwent selection pressure over time and how their biological mechanisms act to express the traits of interest, such as muscle growth and fat deposition. In this sense, we aimed to investigate selection signatures in TT broiler line by detecting $\mathrm{ROH}$ in the 7th and 16th generations, raised in the years of 1998 and 2007, respectively, and estimating $\mathrm{F}_{\mathrm{ST}}$ statistic between these two generations. The identification of those regions will provide better understanding of artificial selection effects on broiler lines, and may point out candidate genes and biological mechanisms underlying performance traits.

\section{Methods \\ Ethics statement}

This study followed experimental protocols pertinent to animal experimentation with the approval of the Embrapa Swine and Poultry Ethics Committee on Animal Utilization (CEUA) in Concordia, Santa Catarina State, Brazil, on resolution number $011 / 2010$. It followed the rules of National Council of Animal Experimentation Control (CONCEA) in accordance with international guidelines to guarantee animal welfare.

\section{Chicken population}

Chickens used in this study were from a broiler line developed by the Embrapa Swine and Poultry National Research Center. This line, called TT, was originated from Cornish and White Plymouth Rock breeds, that has been under a multi-trait selection process focused on body weight, feed conversion, cut yields, breast weight, abdominal fat, and other traits, since 1992 [17, 23, 24]. The chickens were raised in open sided poultry houses, receiving commercial broiler diet and water ad libitum [17, 24]. Chickens were euthanized by cervical dislocation at 42 days of age. Two groups of animals from this line were analyzed, 14 chickens (half male and half female) from the seventh-generation (7th) raised in the year of 1998 and 14 male chickens from the sixteenth-generation (16th) raised in 2007.

The performance of birds from the 7 th generation, as hatched average live weight at 35 days of age was 2272 g; the breast area in the live bird was $96,1 \mathrm{~cm}^{2}$ and the individual feed conversion rate (FCR) for males, from 36 to 43 days of age was $2268 \mathrm{~g}$. The performance of birds from 16th, as hatched average live weight at 42 days of age was $2457 \mathrm{~g}$; the breast area was $112 \mathrm{~cm}^{2}$ and the individual FCR from 43 to 49 days of age was $2798 \mathrm{~g}$ [17]. Note that the age of selection for BW and BA has changed from 35 to 42 days of age in the described period, as well as the FCR evaluation period, which has changed from 36 to 43 days in 1998 to 43-49 days of age in 2007.

\section{Sequencing and quality control}

Whole genome sequencing (WGS) data of 28 chickens were used in this study. Animals were individually sequenced to a minimum coverage of $11.4 \mathrm{x}$ using the HiSeq2500 (Illumina) platform, and the alignment of reads was done against the chicken genome assembly (Gallus gallus-5.0, UCSC) chicken reference genome using Bowtie2 [25]. Detailed information about library preparation, sequencing, quality control of reads, alignment and SNP and INDEL identification are fully described in Boschiero et al. [22] and Moreira et al. [26]. Variants identified in 
sexual, mitochondrial, random or unplaced chromosomes were removed from our analysis.

\section{Principal component analysis}

Genetic relationship between the 28 animals was assessed with a principal component analysis (PCA) using the SNP dataset $(n=9,914,904)$. The analysis was performed using the SNPRelate package of Bioconductor by means of an in-house script in R.

\section{Identification of runs of homozygosity}

The identification of $\mathrm{ROH}$ was chosen to obtain information about selection signatures and how they are shared between animals in both generations. Analyses were performed using PLINK v1.9 software [27, 28], which uses a sliding window approach: a window, with a minimum size, slides across the genome, calling a segment if it is in accordance with the parameters established and the threshold of calculated proportion of homozygous windows overlapping each SNP in that segment. The parameters used in the analysis were set based on Ceballos et al. [29] and they are listed in Table 1.

Dataset of the 28 animals comprised 9,914,904 SNP, and all INDEL were excluded. The parameter -homozyggroup was also used to obtain information of the overlapping $\mathrm{ROH}$ (pools), i.e., $\mathrm{ROH}$ that appeared in at least two animals in the same region of the genome. The output plink.hom.overlap shows each $\mathrm{ROH}$ of each animal overlapping and their respective union $(\mathrm{uROH})$ and consensus sequences $(\mathrm{cROH})$, besides their genome position, size and number of SNP. The consensus $\mathrm{ROH}$ (cROH, i.e. a consensus segment of $\mathrm{ROH}$ that appeared in a common region in at least two animals) of the pools were used for annotation and enrichment analysis, to avoid randomly assigned $\mathrm{ROH}$ and to represent what changed and what is conserved between the animals [30, 31]. In addition, we used an in-house script in $\mathrm{R}$ to check the overlap between the regions of all $\mathrm{cROH}$ and the $\mathrm{ROH}$ previously identified in the TT Reference population (originated from TT broiler line) by Marchesi et al. [17], given the positional coordinates (chromosome, start and end) of these regions and considering at least one overlapped base pair.

\section{Genomic inbreeding coefficients}

Individual genomic inbreeding coefficients were calculated based on $\mathrm{ROH}$ data $\left(\mathrm{F}_{\mathrm{ROH}}\right)$, as defined by McQuillan et al. [32], to know if there was a difference of inbreeding between the 7th and 16th generations. $\mathrm{F}_{\mathrm{ROH}}$ was calculated as:

$$
F_{R O H}=\frac{L_{R O H}}{L_{\text {aut }}},
$$

where $\mathrm{L}_{\mathrm{ROH}}$ is the total size of $\mathrm{ROH}$ in the genome and $\mathrm{L}_{\text {aut }}$ is the total size of autosomal genome covered by SNP of an individual (933.071 Mb, Gallus_gallus-5.0 chicken reference genome - UCSC).

\section{$\mathrm{F}_{\mathrm{ST}}$ analysis}

This method was applied to compare the two generations, i.e. to identify selection signatures by estimating the differences in allele frequency between the 7th and 16th generations. The fixation index was calculated according to Weir and Cockerham's pairwise estimator method [33] using VCFtools v.1.16 software [34], in which SNP and INDEL analyses were run separately, comprising datasets of 9,914,904 SNP and 793,603 INDEL. The same parameters used recently in chickens by Boschiero et al. [22] were applied: $\mathrm{F}_{\mathrm{ST}}$ values were calculated using overlapping windows of $20 \mathrm{~Kb}$ size sliding by steps of $10 \mathrm{~Kb}$ size. Windows with less than 10 SNP or 5 INDEL were removed, and all negative values were set to zero. $\mathrm{F}_{\mathrm{ST}}$ values of the remaining windows were ranked, and those equal or above 0.3 were considered as candidate selection

Table 1 PLINK parameters for run of homozygosity $(\mathrm{ROH})$ analysis

\begin{tabular}{|c|c|c|}
\hline Parameter & Value & Definition \\
\hline -homozyg-snp & 50 & Minimum number of SNP required to consider a $\mathrm{ROH}$; \\
\hline -homozyg-kb & 300 & Size (Kb) of the sliding window; \\
\hline -homozyg-density & 50 & Minimum density required to consider a $\mathrm{ROH}$; \\
\hline -homozyg-gap & 1000 & $\begin{array}{l}\text { Maximum size }(\mathrm{Kb}) \text { between two SNP to be considered } \\
\text { in the same } \mathrm{ROH} \text {; }\end{array}$ \\
\hline -homozyg-window-snp & 50 & Number of SNP present in the sliding window; \\
\hline -homozyg-window-het & 3 & Number of heterozygous SNP allowed in a $\mathrm{ROH}$; \\
\hline $\begin{array}{l}\text {-homozyg-window- } \\
\text { missing }\end{array}$ & 5 & Number of missing calls allowed in a $\mathrm{ROH}$; \\
\hline -homozyg-window-threshold & 0.05 & $\begin{array}{l}\text { Proportion of overlapping windows that must be called } \\
\text { homozygous to define a given SNP as in a homozygous segment. }\end{array}$ \\
\hline
\end{tabular}


signatures. The software BEDTools [35] was used to check if there were equivalent regions identified in both datasets.

\section{Functional analysis}

Functional analysis was performed to identify genes annotated within the candidate selection signature regions identified and, consequently, the biological mechanisms that may be involved with traits of adaptation and performance. Such information was obtained assessing the position (start and end coordinates) of the candidate selection signatures $(\mathrm{cROH}$ and FST windows $\geq 0.3$ ) in the chicken genome available at BioMart Ensembl genome browser platform (Ensembl Genes release 94, Gallus_gallus-5.0 assembly) [36].

We also assessed the genes annotated in the candidate selection signatures under different perspectives in order to understand the effects of selection on TT line in different periods. First, we investigated changes that occurred between the 7th and 16th generations: (i) $\mathrm{cROH}$ of regions shared exclusively among animals of the 7th; (ii) $\mathrm{cROH}$ of regions shared exclusively among animals of the 16th; (iii) $\mathrm{cROH}$ of regions that were shared among at least four animals of the 16th more than animals of 7th; (iv) FST SNP windows ( $\geq 0.3$ ); and (v) FST INDEL windows $(\geq 0.3)$. In addition, we looked for genes annotated in (vi) $\mathrm{cROH}$ of regions shared with 12 or more animals (among the 28), to identify regions probably related to chicken domestication or even, specialization into broilers.

Functional enrichment was performed using $\mathrm{MeSH}$ Enrichment and Semantic Analysis, Bioconductor's package [37, 38], in R software [39] to investigate if there was overrepresentation of any biological processes and components. For such purpose, datasets of genes annotated in the specific candidate selection signatures previously mentioned (i-vi) were analyzed separately. The $p$-value was adjusted using the Benjamin-Hochberg false discovery rate (FDR) method [40].

\section{Overlapping selection signatures with QTL}

In order to confirm the role of the selection signatures detected herein in the regulation of important phenotypes in chickens, we investigated the overlap with QTL associated with traits of economic interest. The analysis was performed using an in-house script in $\mathrm{R}$ to overlap the regions of all $\mathrm{cROH}, \mathrm{F}_{\mathrm{ST}} \mathrm{SNP}$ and INDEL windows against the QTLs available at the Chicken QTL database [41], given the positions (chromosome, start and end) of these regions and considering at least one overlapped base pair. Particularly, we also analyzed if there was overlap of candidate selection signatures with QTL associated with fat deposition previously identified by Moreira et al. [42] in the TT Reference population, originated from an expansion of TT line in 2007 for genomic studies purpose [17].

\section{Results}

\section{Principal component analysis}

Principal component analysis using genomic data revealed a cluster separation between animals of the 7th and the 16th generations (Fig. 1). The distinct clustering demonstrated that genome data successfully separate these animals accordingly to their generation.

\section{Runs of homozygosity}

Analysis of the whole genome sequence data of the 28 animals (14 of the 7th and 14 of the 16th generation) with PLINK's sliding window approach identified 5721 $\mathrm{ROH}$ (1944 in the 7th and 3777 in the 16th generation animals) (Additional file 1). The average number of segments per animal was lower in the 7 th $(138.9 \mathrm{ROH} /$ animal) than in the 16th generation $(269.8 \mathrm{ROH} /$ animal $)$ (Table 2). The ROH presented small and moderate sizes, ranging between $300 \mathrm{~Kb}$ and $4.9 \mathrm{Mb}$, and most of them had sizes smaller than $1.0 \mathrm{Mb}$ in both generations (1821 $\mathrm{ROH}$ in the 7th and 3120 in the 16th generation animals). A change in the distribution of $\mathrm{ROH}$ sizes was also observed between both generations (Fig. 2). The proportion of $\mathrm{ROH}$ smaller than $1.0 \mathrm{Mb}$ decreased (93.7\% in the 7th to $82.6 \%$ in 16th generation) while the proportion of $\mathrm{ROH}$ with sizes between 1.0 and $2.0 \mathrm{Mb}$ increased $\left(6.1 \%\right.$ in the 7 th to $14.7 \%$ in the $16^{\text {th }}$ generation) as well as $\mathrm{ROH}$ bigger than $2.0 \mathrm{Mb}(0.3 \%$ in the 7 th to $2.7 \%$ in 16 th generation). The average total size of $\mathrm{ROH}$ per animal was $73.2 \mathrm{Mb}$ in the 7 th and $188.6 \mathrm{Mb}$ in the 16th generation (Table 2).

$\mathrm{ROH}$ were identified in all chromosomes, except on GGA16 and GGA30-32 (Table 3). Figure 3 represents all $\mathrm{ROH}$, with their proportional sizes, distributed across GGA2 for the 28 animals. Regions where $\mathrm{ROH}$ is presented in more than one animal formed a sharing pattern. Figures of other chromosomes are provided as Additional file 2. The four longest $\mathrm{ROH}(>4 \mathrm{Mb})$ were located on different macro chromosomes (GGA2: 116, 060,874 - 120,088,450; GGA5: 39,097,092 - 43,183,508; GGA3: 25,504,098 - 29,639,462; GGA4: 69,071,022 $73,960,022)$. Overlaps of $\mathrm{ROH}$ from at least two animals established 1941 pools (Additional file 3). There was one pool of ROH shared among the 28 animals, and it was located in the GGA2 with a consensus sequence of 300.2 $\mathrm{Kb}(82,146,603-82,446,837)$. Furthermore, most of the pools consisted in regions shared among two to seven animals (74.4\%). There were 87 regions with $\mathrm{ROH}$ commonly shared with at least 12 animals, and most of them identified on GGA1. 


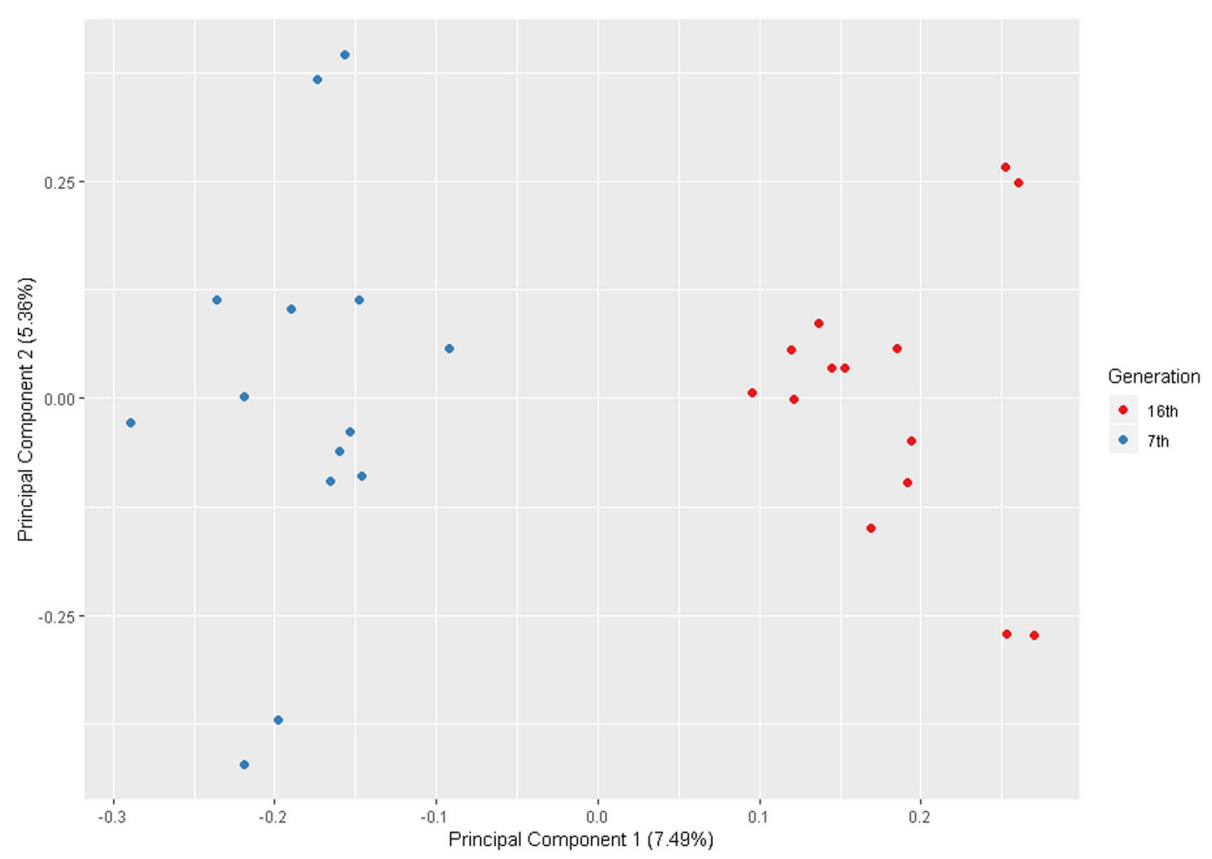

Fig. 1 Principal component analysis using genomic data $(S N P=9,914,904)$ for 7 th and 16th generations

Regions commonly shared among the animals become more frequent in the 16th generation. We observed a greater number of $\mathrm{ROH}$ pools shared among animals from 16th generation than animals from 7th generation (Fig. 4-a, b and c).

\section{Genomic inbreeding coefficients}

Individual genomic inbreeding coefficients based on $\mathrm{ROH}\left(\mathrm{F}_{\mathrm{ROH}}\right)$ were calculated for both generations (Table 2). Mean, maximum and minimum individual $F_{R O H}$ for animals of the 7th generation were $0.0784,0.1340$, and 0.0215 , respectively, with a coefficient of variation $(\mathrm{CV})$ of $52.8 \%$. For animals of the 16th, the mean, maximum and minimum individual $\mathrm{F}_{\mathrm{ROH}}$ were $0.2021,0.2213$, and $0.1761(\mathrm{CV}=7.4 \%)$.

\section{$\mathrm{F}_{\mathrm{ST}}$ windows}

$\mathrm{F}_{\mathrm{ST}}$ analysis identified 91,638 and 86,404 windows for SNP and INDEL datasets, respectively, after removing windows with less than 10 SNP and five INDEL. The number of markers per window ranged from 10 to 1562 SNP (average of $216.3 \mathrm{SNP} /$ window) and from five to $72 \mathrm{INDEL}$ (average of 18.2 INDEL/window). Mean $\mathrm{F}_{\mathrm{ST}}$ values for SNP and INDEL datasets were 0.040 and 0.038 , respectively, while the highest $\mathrm{F}_{\mathrm{ST}}$ values were 0.598 and 0.555 .

Windows with FST values equal or higher than 0.3 were considered candidate selection signatures. There were 178 windows using SNP dataset (Fig. 5) and 154 windows using INDEL dataset (Fig. 6) above this threshold value $(\mathrm{FST} \geq 0.3)$. More information about these windows are available in the Additional files 5 and 6. Most of these windows were in the macrochromosomes (Table 3 ) and approximately $87 \%$ of the INDEL windows overlapped with SNP windows (Fig. $4-\mathrm{c}$ and d).

\section{Genes in consensus selection signature regions}

Annotation analysis using the Ensembl genome browser revealed 5681 genes annotated in the 1941 cROH pools shared among at least two of the 28 animals (Additional file 7). Annotation of $\mathrm{F}_{\mathrm{ST}}$ windows (Fst $\geq 0.3$ ) identified 56 and 60 genes for SNP and INDEL datasets, respectively (Additional files 8 and 9). Since a great part of SNP windows overlapped with INDEL windows, 37 of these genes were common for both datasets (Table 4). In addition, about $46.1 \%$ of SNP $\mathrm{F}_{\mathrm{ST}}$ windows and $37.7 \%$ of INDEL $\mathrm{F}_{\mathrm{ST}}$ windows overlapped with cROH. Thus, we found 34 genes annotated in $\mathrm{cROH}$ in common with genes annotated in FST (SNP and/or INDEL) windows (Table 4).

Based on Biomart Ensembl database, some of the genes commonly annotated in Fst and cROH regions, plays a role in biological processes involved in traits of economic interest in chicken or in other model animals; all the biological processes related to the genes mentioned in Table 4, are available at Additional file 10. There were genes involved in lipid metabolic processes, glucose metabolism and homeostasis and adipose tissue development. Other genes were described to be involved in muscle cell differentiation, muscle tissue development, and constituents of 
Table $2 \mathrm{ROH}$ features for each animal of 7th and 16th generations

\begin{tabular}{|c|c|c|c|c|}
\hline $\mathrm{IID}$ & Number of $\mathrm{ROH}^{\mathrm{a}}$ & Total size $^{\mathrm{b}}(\mathrm{Kb})$ & Mean size of segments $(\mathrm{Kb})$ & $\mathrm{F}_{\mathrm{ROH}}$ \\
\hline 7th_01 & 130 & $60,492.6$ & 465.328 & 0.0648 \\
\hline $7^{\text {th }}-02$ & 212 & $125,062.0$ & 589.913 & 0.1340 \\
\hline $7^{\text {th }}-03$ & 131 & $63,732.1$ & 486.504 & 0.0683 \\
\hline $7^{\text {th }}-04$ & 61 & $25,416.8$ & 416.668 & 0.0272 \\
\hline $7^{\text {th }}-05$ & 65 & $30,014.6$ & 461.763 & 0.0322 \\
\hline $7^{\text {th }}-06$ & 85 & $38,303.9$ & 450.634 & 0.0411 \\
\hline $7^{\text {th }}-07$ & 183 & $103,302.0$ & 564.491 & 0.1107 \\
\hline $7^{\text {th }}-08$ & 148 & $71,381.7$ & 482.309 & 0.0765 \\
\hline $7^{\text {th }}-09$ & 209 & $138,608.0$ & 663.195 & 0.1486 \\
\hline $7^{\text {th }}-10$ & 219 & $128,120.0$ & 585.024 & 0.1373 \\
\hline $7^{\text {th }}-11$ & 94 & $42,055.7$ & 447.401 & 0.0451 \\
\hline $7^{\text {th }}-12$ & 175 & $82,420.5$ & 470.974 & 0.0883 \\
\hline $7^{\text {th }}-13$ & 188 & $95,302.7$ & 506.929 & 0.1021 \\
\hline $7^{\text {th }}-14$ & 44 & $20,107.3$ & 456.985 & 0.0215 \\
\hline Means (CV) of the $7^{\text {th }}$ generation & $139(43.8 \%)$ & $73,165.7(54.8 \%)$ & $503,437(13.9 \%)$ & $0,0784(54.8 \%)$ \\
\hline 16th_01 & 245 & $164,355.0$ & 670.839 & 0.1761 \\
\hline $16^{\text {th }}-02$ & 241 & $183,336.0$ & 760.729 & 0.1965 \\
\hline $16^{\text {th }}-03$ & 254 & $174,906.0$ & 688.608 & 0.1875 \\
\hline $16^{\text {th }}-04$ & 280 & $200,919.0$ & 717.567 & 0.2153 \\
\hline $16^{\text {th }}-05$ & 268 & $188,023.0$ & 701.579 & 0.2015 \\
\hline $16^{\text {th }}-06$ & 318 & $200,111.0$ & 629.281 & 0.2145 \\
\hline $16^{\text {th }}-07$ & 256 & $181,422.0$ & 708.681 & 0.1944 \\
\hline $16^{\text {th }}-08$ & 290 & $196,574.0$ & 677.843 & 0.2107 \\
\hline $16^{\text {th }}-09$ & 289 & $206,456.0$ & 714.381 & 0.2213 \\
\hline $16^{\text {th }}-_{10}$ & 283 & $215,635.0$ & 761.963 & 0.2311 \\
\hline $16^{\text {th }}-11$ & 275 & $187,931.0$ & 683.386 & 0.2014 \\
\hline $16^{\text {th }}-12$ & 254 & $181,634.0$ & 715.095 & 0.1947 \\
\hline $16^{\text {th }}-13$ & 242 & $167,875.0$ & 693.697 & 0.1799 \\
\hline $16^{\text {th }}-_{14}$ & 282 & $191,333.0$ & 678.484 & 0.2051 \\
\hline Means $(\mathrm{CV})$ of the $16^{\text {th }}$ generation & $270(8.3 \%)$ & $188,607.9(7.7 \%)$ & $700.152(4.9 \%)$ & $0.2021(7.7 \%)$ \\
\hline
\end{tabular}

IID individual identification, $\mathrm{CV}$ coefficient of variation \%

${ }^{\mathrm{a}}$ Total number of $\mathrm{ROH}$ identified in each animal

${ }^{\mathrm{b}}$ Total size of autosomal genome covered by $\mathrm{ROH}$

skeletal muscle. Moreover, there were a group of genes related to different types of behavior, such as grooming, locomotion, fear response, feeding behavior, aggressiveness, and social, exploration and maternal behaviors. Genes involved in the immune humoral system, differentiation, proliferation, homeostasis and chemotaxis of B cells, and regulation of cytokines production were also annotated in regions of the candidate selection signatures.

In order to complement the Fst analysis we identified genes in $\mathrm{cROH}$ regions that were either exclusive between the 7th and 16th generations. There were 71 genes annotated in the regions that were in homozygosity only in the 7th generation and 1881 genes annotated in regions of cROH shared only among animals of the 16th generation. We also identified genes in cROH regions that had changed between the 7th and 16th generations. For that, we considered regions that either increased or decreased by at least four animals in $\mathrm{cROH}$ regions between generations. There were 1318 genes annotated on these regions. For example, the gene IGF-I (GGA1 55,335,204 - 55,383, 631) was annotated in a cROH region (GGA1 55,149,208 - 55,359,089) shared between seven animals of the 7th and 13 animals of the 16th. Additional file 11 presents genes annotated in these regions and that were previously associated with traits of economic interest in chickens.. 


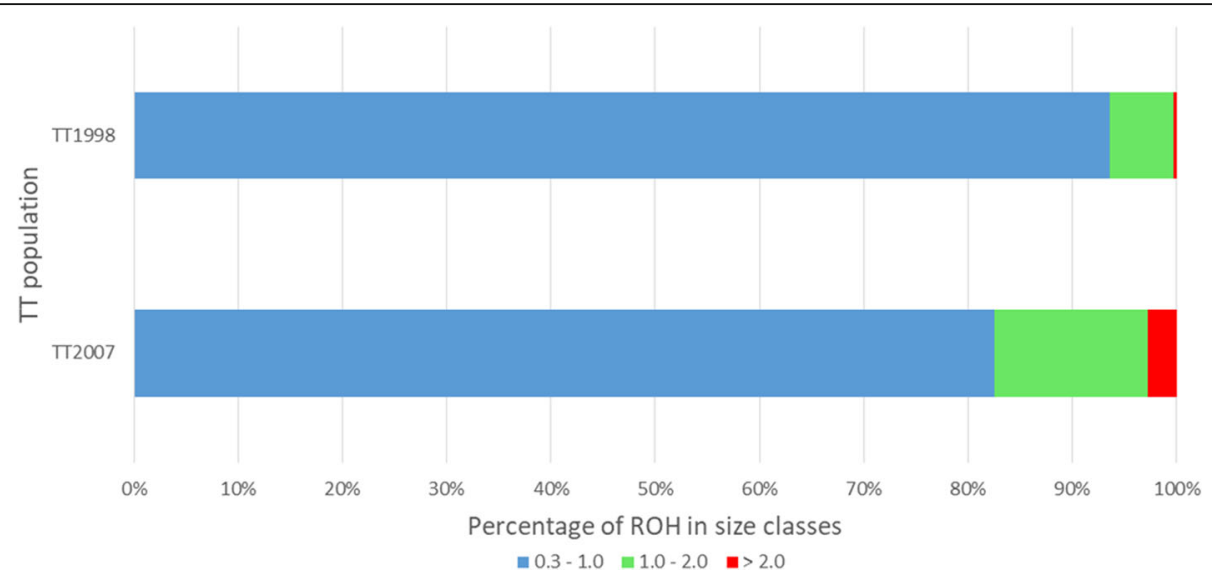

Fig. 2 Percentage of $\mathrm{ROH}$ in 7 th and 16th generations distributed in size classes. A decrease in the proportion of ROH smaller than $1.0 \mathrm{Mb}$ in 16th is observed, meanwhile the proportions of $\mathrm{ROH}$ with sizes above $1.0 \mathrm{MB}$ increased

Table 3 Summary of runs of homozygosity $(\mathrm{ROH})$, pools of ROH, $\mathrm{F}_{S T}$ SNP windows, and $\mathrm{F}_{S T}$ INDEL windows by chromosome in $\Pi$ population in all animals from 7th and 16th generations

\begin{tabular}{|c|c|c|c|c|c|}
\hline$\overline{G G A}$ & Size $(\mathrm{Mb})$ & Number of $\mathrm{ROH}$ & Number of pools & Number of FST SNP windows $(\geq 0.3)$ & Number of FST INDEL windows ( $\geq 0.3$ ) \\
\hline 1 & 196.20 & 1230 & 415 & 53 & 65 \\
\hline 2 & 149.56 & 1087 & 338 & 28 & 28 \\
\hline 3 & 111.30 & 609 & 228 & 28 & 23 \\
\hline 4 & 91.28 & 582 & 212 & 5 & 4 \\
\hline 5 & 59.83 & 392 & 137 & 6 & 9 \\
\hline 6 & 35.47 & 211 & 77 & 4 & 5 \\
\hline 7 & 36.95 & 267 & 85 & 17 & 21 \\
\hline 8 & 29.96 & 213 & 66 & 1 & 2 \\
\hline 9 & 24.09 & 106 & 39 & 6 & 10 \\
\hline 10 & 20.44 & 106 & 39 & - & 2 \\
\hline 11 & 20.22 & 114 & 36 & 1 & 1 \\
\hline 12 & 19.95 & 90 & 41 & - & - \\
\hline 13 & 18.41 & 107 & 35 & 1 & 2 \\
\hline 14 & 15.60 & 101 & 32 & - & 1 \\
\hline 15 & 12.76 & 81 & 32 & - & - \\
\hline 17 & 10.96 & 72 & 22 & - & - \\
\hline 18 & 11.05 & 87 & 28 & 1 & - \\
\hline 19 & 9.98 & 61 & 16 & - & 2 \\
\hline 20 & 14.11 & 54 & 19 & - & - \\
\hline 21 & 6.86 & 26 & 7 & - & - \\
\hline 22 & 4.73 & 13 & 4 & 2 & 3 \\
\hline 23 & 5.79 & 21 & 7 & 1 & - \\
\hline 24 & 6.28 & 30 & 12 & - & - \\
\hline 25 & 2.91 & 7 & 1 & - & - \\
\hline 26 & 5.31 & 9 & 1 & - & - \\
\hline 27 & 5.66 & 16 & 5 & - & - \\
\hline 28 & 4.97 & 25 & 6 & - & - \\
\hline 33 & 1.65 & 4 & 1 & - & - \\
\hline
\end{tabular}




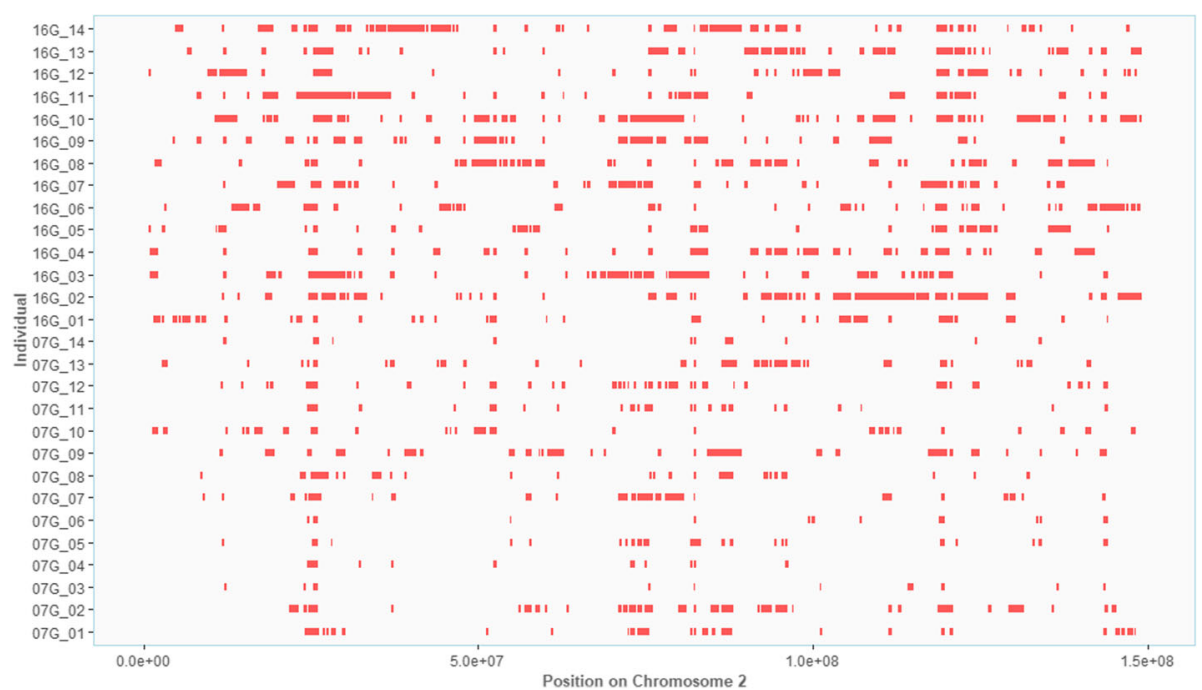

Fig. 3 Genome wide distribution of runs of homozygosity (ROH) in TT population. Size and location of ROH in chromosome 2 for each animal are represented in parallel. Patterns of shared $\mathrm{ROH}$ can be observed in some regions of the chromosome. In addition, a higher frequency of ROH in animals of $16 \mathrm{G}$ was observed

These different gene lists were used to perform MeSH overrepresentation analysis, with the purpose of having an integrated knowledge of biological processes may be involved in the selection of TT line. MeSH analysis indicates if there is an overrepresentation of a particular group of genes in a biological category, such as anatomy, diseases or phenomena and processes. In this sense, overrepresentation analysis resulted in eight different biological terms: 'matrilin proteins', 'skeletal muscle, 'Salmonella infections in animals, 'adipose tissue,' 'cystatins', 'tyrosine', 'pregnancy in diabetics', and 'hyperglycemia'. Table 5 presents each one of these terms and their respective gene counts and $p$-values.

\section{Selection signatures in overlap with QTL in the TT line}

To identify selection signatures associated with quantitative traits, we investigated the overlap between the regions of $\mathrm{cROH}, \mathrm{F}_{\mathrm{ST}} \mathrm{SNP}$ and INDEL windows $(\geq 0.3)$ with QTL regions previously associated with traits of economic interest in chickens available at the Chicken QTL database (release 37). About $72.8 \%$ of the $1941 \mathrm{cROH}$ overlapped with QTL regions $(n=2617)$. There were also overlap of $60.1 \%$ of the $178 \mathrm{~F}_{\mathrm{ST}} \mathrm{SNP}$ windows and $68.2 \%$ of the $154 \mathrm{~F}_{\mathrm{ST}}$ INDEL windows with QTL regions ( $n=107$ and 105, respectively). These QTL regions were associated with 143 different traits (Additional file 12) of which some are very important for broilers' breeding program goals such as feed conversion rate, feed intake, average daily gain, body weight, breast muscle weight, and others (Figs. 7, 8 and 9).

We also identified cROH regions that overlapped with 10 QTL previously mapped for fatness traits on GGA5, GGA9, GGA10, GGA13, GGA15, and GGA27 in the same population utilized herein (TT Reference Population)
(Table 6) [42]. There was no overlap between the $\mathrm{F}_{\mathrm{ST}}$ windows ( $\geq 0.3)$ and these QTLs mapped for fatness.

\section{Discussion}

\section{Runs of homozygosity}

$\mathrm{ROH}$ studies have addressed human evolution and diseases, conservation and evolution of wild species, and genomic features of livestock animals [2, 7, 13, 17]. The investigation of $\mathrm{ROH}$ as selection signatures using different generations of the TT line provided two new insights. First, the identification of important selection signatures that may refer to periods preceding the generations under study. Second, it allowed the comparison of how these selection signatures were shared among the individuals and how they have changed over the generations. Since shared $\mathrm{ROH}$ is an indication of regions under selection [18], the consensus regions of $\mathrm{ROH}(\mathrm{cROH})$ were used in this study to understand the possible biological consequences of selection in this broiler line.

The $\mathrm{ROH}$ identified in animals of TT line presented small to moderate sizes, ranging from $300 \mathrm{~Kb}$ to $4.9 \mathrm{Mb}$. Short $\mathrm{ROH}$ are most probable to be IBD genomic regions inherited from ancient ancestors indicating long term selection [43]. Over the generations, IBD segments tends to break down due to recombination events by repeated meiosis. Thus, $\mathrm{ROH}$ size is associated with the degree of shared parental ancestry and for how long it was passed across generations [32] and, as expected, short $\mathrm{ROH}$ regions shared between animals of the 7th and 16th generations encompassed genes associated with traits of interest (Additional file 10). It is important to mention that not all short $\mathrm{ROH}$ are IBD and a proportion of them may be identical-by-state (IBS) due to genetic drift, as well as 


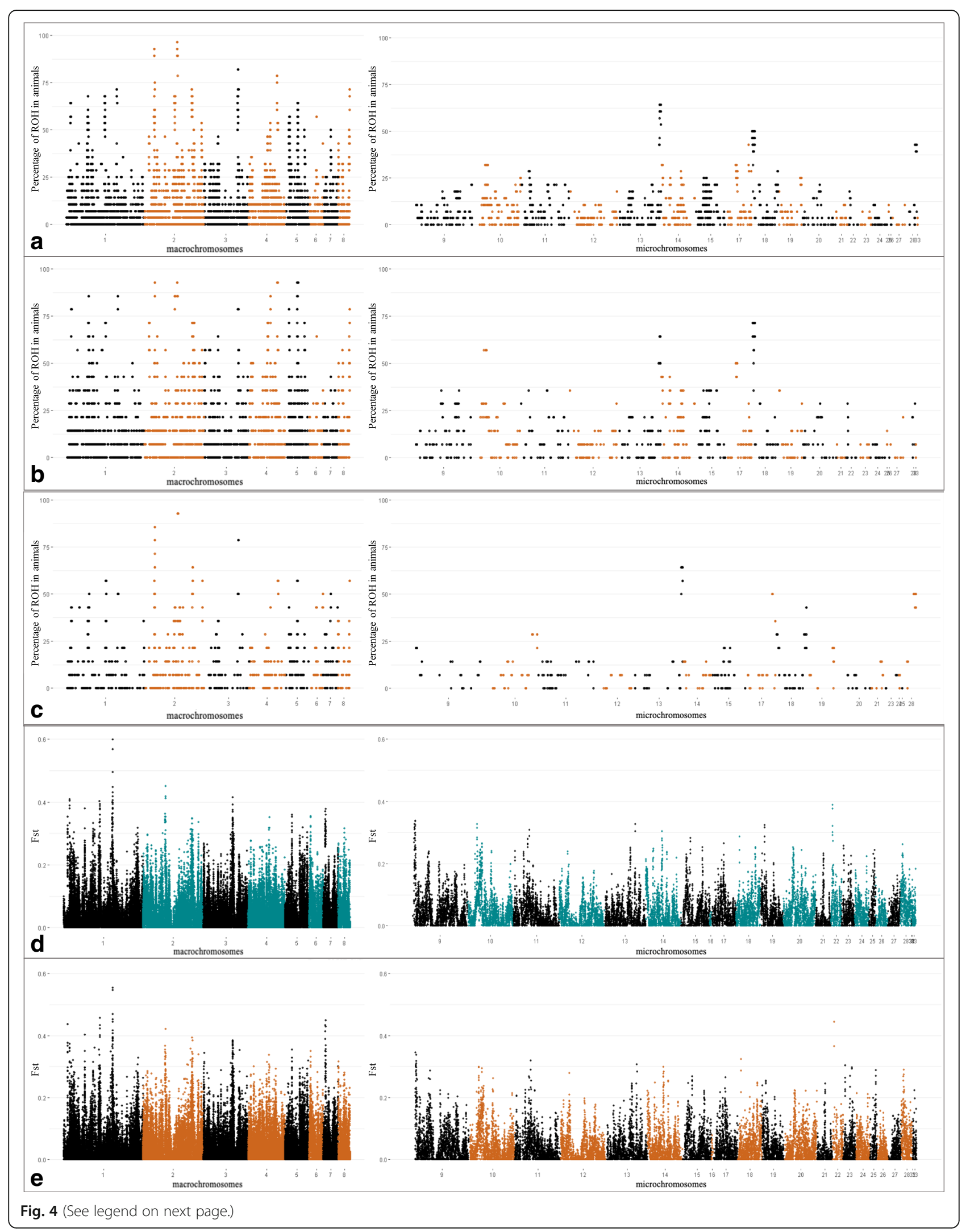


(See figure on previous page.)

Fig. 4 Manhattan plot of genomic regions and percentage of animals that shares the candidate selection signatures as well, SNPs and INDELs Fst windows. a: ROH pools detected in all the 28 animals; $\mathbf{b}$ : ROH pools detected in the 14 birds from 16th generation; $\mathbf{c}$ : ROH pools detected in the 14 birds from 7th generation; d: SNPs Fst windows; e: INDELS Fst windows. For $\mathbf{a}$, $\mathbf{b}$ and $\mathbf{c}$, the X-axis represents the chromosomes, and Y-axis shows the proportion of animals that shares the ROH pools. For $\mathbf{d}$ and $\mathbf{e}$, the $\mathrm{X}$-axis represents the chromosomes, and $\mathrm{Y}$-axis shows the Fst values

population bottlenecks, and therefore some authors recommend caution in attributing these regions as candidate selection signatures $[18,44,45]$. The minimum size of 300 $\mathrm{Kb}$ was set in our analysis to detect $\mathrm{ROH}$, considering that the use of WGS data calls ROH with smaller sizes compared to SNPchip data. A limitation in our study is that we were not able to determine which proportion of $\mathrm{ROH}$ is attributed to genetic drift and may lead to false positives. However, strategies were adopted to improve the chances to detect true selection signatures associated with the selection program. They were (i) using $\mathrm{ROH}$ regions in common with at least two animals, (ii) overlapping these regions with the Chicken QTL database, and (iii) performing $\mathrm{MeSH}$ overrepresentation analysis. These combined strategies reduce the chance to detect candidate selection signatures due to genetic drift.

In a study with offspring from animals of the 16th generation, Marchesi et al. [17] identified $\mathrm{ROH}$ in 1279 chickens using a high-density $600 \mathrm{~K}$ genotyping array data. They adopted the same parameters used in the present study, except for the minimum size of $\mathrm{ROH}$ and number of heterozygous SNP allowed. As expected, regions of $\mathrm{ROH}$ were commonly shared between both populations. More than $98 \%$ of the cROH identified herein in animals of the 16th generations, overlapped with $\mathrm{ROH}$ identified in the study of Marchesi et al. [17], corroborating our findings (Additional file 4). However, a higher number of $\mathrm{ROH}$ per animal and $\mathrm{ROH}$ with smaller sizes were identified in the 28 animals compared to those of Marchesi et al. [17]. We suggest that the reasons for identifying shorter $\mathrm{ROH}$ relies on the higher resolution of WGS data in comparison with SNPchip data. This difference in $\mathrm{ROH}$ calling was also observed in another study with feline that used both types of dataset for the same individuals [46].

It is also important to highlight that low coverage WGS data may present higher error rate of variant calling in comparison with SNPchip data, and this may lead to inaccuracy of $\mathrm{ROH}$ calling [29]. Thus, we followed parameters based on Ceballos et al. [29], which demonstrated equivalent results to SNPchip data's results, when dealing with low coverage WGS. Moreover, in order to extend the chances of detecting accurate $\mathrm{ROH}$, we opted to investigate consensus regions of $\mathrm{ROH}$, i.e. regions of $\mathrm{ROH}$ in common with at least two animals, that might indicate regions under selection $[18,30]$. All these observations corroborate with our suggestion that the smaller size and higher number of $\mathrm{ROH}$ possibly relies on the better resolution of WGS.

In our study, an increase in $\mathrm{ROH}$ abundance was observed, i.e. between the 7th and 16th generations there was an increase on the average number of $\mathrm{ROH}$ segments per animal and in the average size of segment per animal (Fig. 2 and Table 2). Investigation of the history of the breeding program indicate that these differences may have occurred due to a bottleneck effect. Marchesi et al. [17] estimated the $\mathrm{N}_{\mathrm{e}}$ in TT line backing to 200 generations ago and reported a decay in $\mathrm{N}_{\mathrm{e}}$, especially in the last five generations, ranging from 157 to 113 chickens $\left(\mathrm{N}_{\mathrm{e}}\right.$ of TT Reference Population). Thus, when a population size is reduced, the average of heterozygosity in a certain locus is expected to decline, depending on the $\mathrm{N}_{\mathrm{e}}[47,48]$. The occurrence of a bottleneck effect is supported by the observed increase in the mean genomic inbreeding coefficient from the 7th to the 16th generation (7th $\mathrm{F}_{\mathrm{ROH}}=0.078$ and 16th $\mathrm{F}_{\mathrm{ROH}}=0.202$ ). It

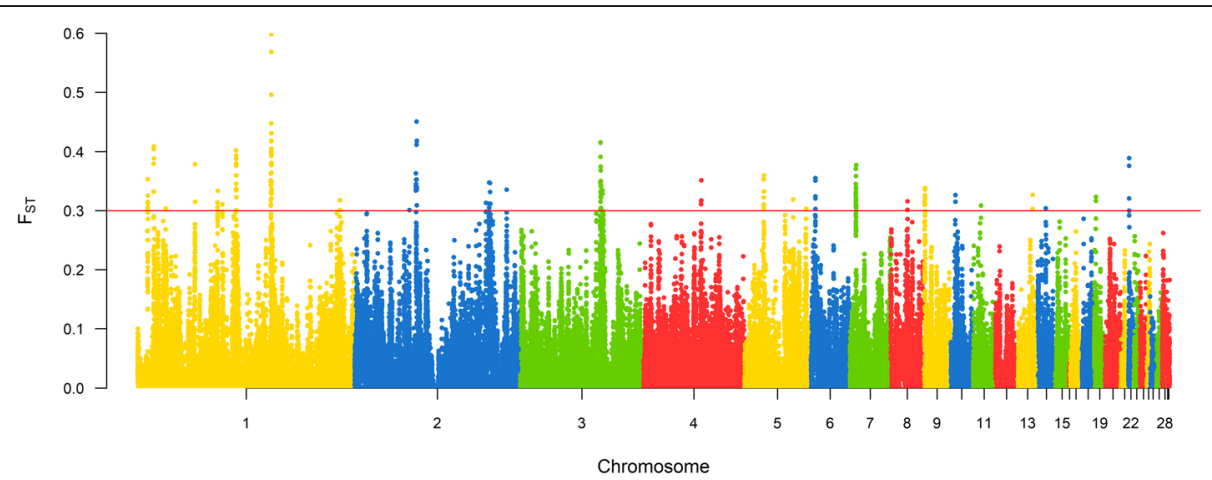

Fig. 5 Manhattan plot of genome wide distribution of $F_{S T}$ windows for SNP dataset. Red line represents threshold of 0.3, windows above this value were considered candidate selection signature 


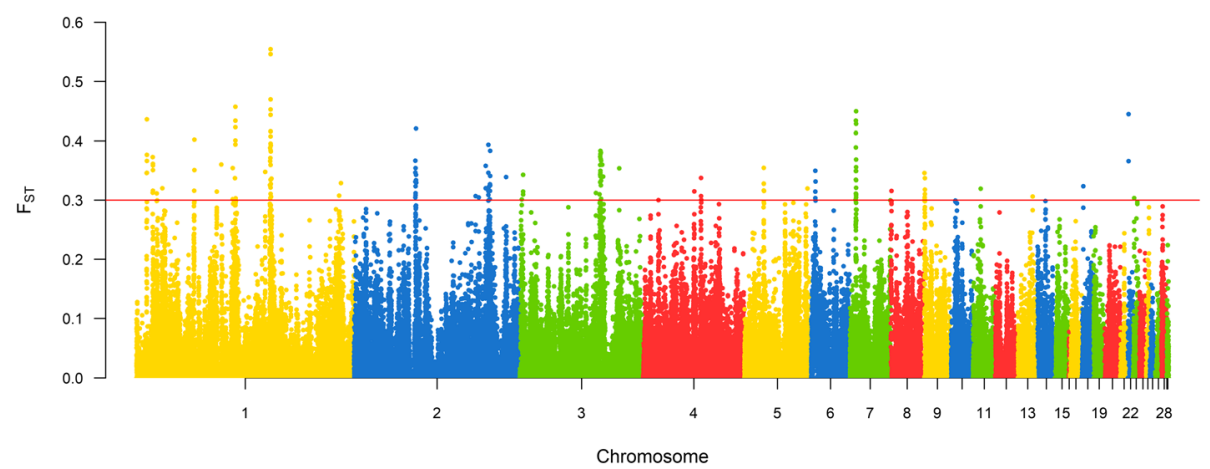

Fig. 6 Manhattan plot of genome wide distribution of $\mathrm{F}_{S T}$ windows for INDEL dataset. Red line represents threshold of 0.3, windows above this value were considered candidate selection signatures

is worth to mention that, even if mating between close related individuals is avoided some level of inbreeding is unavoidable, because TT line is a closed population [17].

Furthermore, the percentage of animals sharing a $\mathrm{ROH}$ region increased from the 7th to the 16th generation (Fig. 4). Mastrangelo et al. [18] reported similar observations of an increase in the abundance of $\mathrm{ROH}$ in a sheep breed it and suggested that a decrease in the effective population size $\left(\mathrm{N}_{\mathrm{e}}\right)$ had occurred resulting in recent and historical autozygosity events. Thus, we suggest that the increase in homozygous regions across generations in TT line is consequence of selection pressure over genomic regions that are important to the breeding program's goals jointly to reduction on the $\mathrm{N}_{\mathrm{e}}$ and inbreeding. In fact, genes associated with traits of economic interest, such as the $A P O B, P O M C, P P A R G$ and other genes (Additional file 10), were annotated in regions shared with more animals of the 16th than with 7th generation, supporting that the regions containing these genes were under selection pressure in the respective period.

\section{$\mathrm{F}_{\mathrm{ST}}$ windows}

An alternative approach applied in this study for identification of selection signatures was the genetic differentiation method based on allele frequency differences called $\mathrm{F}_{\mathrm{ST}}$ statistics. Previous studies have used this method for detecting selection signature in livestock species, such as broilers [14, 21, 22, 49, 50]. Here we compared two groups of animals of TT broiler line, 10 generations distant from each other. The parameters were the same used by Boschiero et al. [22], in the comparison of the TT line against a layer line. The authors states that windows of $20 \mathrm{~Kb}$ allow a finer resolution of the regions in addition to windows with sufficient number of markers, considering that the amount of variants in a window is essential for increasing the power of the analysis $[22,51]$. This intent was achieved in our results since we obtained an average of $216 \mathrm{SNP} /$ window and
18 INDEL/window, which were similar to the results obtained by Boschiero et al. [22] with averages of $268 \mathrm{SNP} /$ window and $26 \mathrm{INDEL} /$ window. Furthermore, there was a considerable number of windows in common between SNP and INDEL datasets with $87 \%$ of overlapping, a fact also observed by Boschiero et al. [22].

Estimates of $\mathrm{F}_{\mathrm{ST}}$ range from zero, meaning no genetic difference between the subpopulations, up to 1.0, meaning complete genetic differentiation [52]. Although there is not a determined threshold to capture regions that indicate genetic differentiation as a candidate selection signature, some authors use a threshold for the top $0.1 \%$ values of $\mathrm{F}_{\mathrm{ST}}[21,22]$. Here we established a threshold value of 0.3 in order to obtain regions that might be in a differentiation process in the TT line. Only $0.002 \%$ of the windows had $\mathrm{F}_{\mathrm{ST}}$ values above this threshold, for SNP and INDEL datasets, and the highest estimated values were 0.598 and 0.555 for SNP and INDEL datasets, respectively. In addition, as discussed by Boschiero et al. [22], combining strategies to detect selection signatures minimizes the occurrence of false positives.

\section{Selection signatures of broiler performance and adaptation}

Besides identifying regions in the chicken genome under selection pressure, knowing the genes annotated in these regions and how they biologically act is essential for understanding how the selection signatures contributed to the current phenotype of the evaluated animals. Since TT broiler line is under multi-trait selection since 1992 aiming to improve body weight, feed conversion, cut yields, breast weight, viability, fertility, and hatchability and to reduce abdominal fat $[17,23]$, it is expected that genes influencing the performance of these traits are under selection pressure.

Therefore, investigating which genes were annotated in the candidate selection signatures regions identified in both $\mathrm{F}_{\mathrm{ST}}$ and $\mathrm{ROH}$ analysis helps to understand the biological mechanisms that affected the construction and 
Table 4 Genes annotated commonly between selection signatures of two or more datasets

\begin{tabular}{|c|c|c|}
\hline Gene ID & Gene name & Description \\
\hline \multicolumn{3}{|c|}{$\overline{F_{S T}}$ SNP and INDEL windows $(\geq 0.3)$ datasets } \\
\hline ENSGALG000000000242 & $E B F 2$ & early B cell factor 2 \\
\hline ENSGALG00000002370 & $\mathrm{SH} 2 \mathrm{D} 4 \mathrm{~B}$ & $\mathrm{SH} 2$ domain containing $4 \mathrm{~B}$ \\
\hline ENSGALG000000002414 & TSPAN14 & tetraspanin 14 \\
\hline ENSGALG00000004045 & AGAP1 & ArfGAP with GTPase domain, ankyrin repeat and PH domain 1 \\
\hline ENSGALG000000004116 & TRPM8 & transient receptor potential cation channel subfamily $\mathrm{M}$ member 8 \\
\hline ENSGALG00000004129 & SPP2 & secreted phosphoprotein 2 \\
\hline ENSGALG000000007555 & CCND1 & cyclin D1 \\
\hline ENSGALG00000007556 & LTO1 & LTO1, ABCE1 maturation factor \\
\hline ENSGALG00000012542 & RASD2 & RASD family member 2 \\
\hline ENSGALG00000015402 & C3orf38 & chromosome 3 open reading frame 38 \\
\hline ENSGALG00000015403 & EPHA3 & EPH receptor A3 \\
\hline ENSGALG00000015570 & GPR63 & G protein-coupled receptor 63 \\
\hline ENSGALG00000015573 & FHL5 & four and a half LIM domains 5 \\
\hline ENSGALG00000016518 & PHKA2 & phosphorylase kinase regulatory subunit alpha 2 \\
\hline ENSGALG00000016522 & PPEF1 & protein phosphatase with EF-hand domain 1 \\
\hline ENSGALG00000016529 & CDKL5 & cyclin dependent kinase like 5 \\
\hline ENSGALG00000016541 & novel gene & BEN domain containing 2 \\
\hline ENSGALG00000016543 & NHS & NHS actin remodeling regulator \\
\hline ENSGALG00000022866 & ZNF654 & zinc finger protein 654 \\
\hline ENSGALG000000026372 & novel gene & -- \\
\hline ENSGALG00000028376 & FGF19 & fibroblast growth factor 19 \\
\hline ENSGALG00000032974 & ADAMTS2 & ADAM metallopeptidase with thrombospondin type 1 motif 2 \\
\hline ENSGALG000000033076 & novel gene & -- \\
\hline ENSGALG00000035116 & STAG1 & stromal antigen 1 \\
\hline ENSGALG00000035393 & $\angle R R C 14 B$ & leucine rich repeat containing $14 \mathrm{~B}$ \\
\hline ENSGALG00000035906 & YTHDC1 & YTH domain containing 1 \\
\hline ENSGALG00000036204 & novel gene & -- \\
\hline ENSGALG000000036327 & NGEF & neuronal guanine nucleotide exchange \\
\hline ENSGALG00000036730 & MRPS35 & mitochondrial ribosomal protein S35 \\
\hline ENSGALG000000036938 & RALYL & RALY RNA binding protein like \\
\hline ENSGALG000000038154 & YAP1 & Yes associated protein 1 \\
\hline ENSGALG000000038730 & GIGYF2 & GRB10 interacting GYF protein 2 \\
\hline ENSGALG00000039139 & TNS3 & tensin 3 \\
\hline ENSGALG00000039690 & STMN2 & stathmin 2 \\
\hline ENSGALG00000039738 & SLC9A3 & solute carrier family 9 member $\mathrm{A} 3$ \\
\hline ENSGALG000000040264 & C9H2ORF82 & chromosome 9 open reading frame, human C2orf82 \\
\hline ENSGALG00000042764 & COG5 & component of oligomeric golgi complex 5 \\
\hline \multicolumn{3}{|c|}{$C R O H$ and $F_{S T} S N P$ windows $(\geq 0.3)$} \\
\hline ENSGALG00000000242 & EBF2 & early B cell factor 2 \\
\hline ENSGALG00000001153 & AUTS2 & AUTS2, activator of transcription and developmental regulator \\
\hline ENSGALG00000003705 & VPS13C & vacuolar protein sorting 13 homolog C \\
\hline ENSGALG00000004045 & AGAP1 & ArfGAP with GTPase domain, ankyrin repeat and PH domain 1 \\
\hline ENSGALG000000004116 & TRPM8 & transient receptor potential cation channel subfamily $\mathrm{M}$ member 8 \\
\hline
\end{tabular}


Table 4 Genes annotated commonly between selection signatures of two or more datasets (Continued)

\begin{tabular}{|c|c|c|}
\hline Gene ID & Gene name & Description \\
\hline ENSGALG000000006237 & PKN2 & protein kinase N2 \\
\hline ENSGALG000000007555 & CCND1 & cyclin D1 \\
\hline ENSGALG000000007556 & LTO1 & LTO1, ABCE1 maturation factor \\
\hline ENSGALG00000015402 & C3orf38 & chromosome 3 open reading frame 38 \\
\hline ENSGALG00000015403 & EPHA3 & EPH receptor $\mathrm{A} 3$ \\
\hline ENSGALG00000016518 & PHKA2 & phosphorylase kinase regulatory subunit alpha \\
\hline ENSGALG00000016522 & PPEF1 & protein phosphatase with EF-hand domain 1 \\
\hline ENSGALG00000016529 & CDKL5 & cyclin dependent kinase like 5 \\
\hline ENSGALG00000022866 & ZNF654 & zinc finger protein 654 \\
\hline ENSGALG00000025253 & gga-mir-1694 & gga-mir-1694 \\
\hline ENSGALG00000028376 & FGF19 & fibroblast growth factor 19 \\
\hline ENSGALG00000030580 & RPS6KA5 & ribosomal protein S6 kinase A5 \\
\hline ENSGALG00000032958 & $A M P H$ & amphiphysin \\
\hline ENSGALG00000034119 & novel gene & collagen type $\mathrm{XV}$ alpha 1 chain \\
\hline ENSGALG00000035116 & STAG1 & stromal antigen 1 \\
\hline ENSGALG00000035906 & YTHDC1 & YTH domain containing 1 \\
\hline ENSGALG00000036938 & RALYL & RALY RNA binding protein like \\
\hline ENSGALG00000038730 & GIGYF2 & GRB10 interacting GYF protein 2 \\
\hline ENSGALG00000040167 & TPD52 & tumor protein D52 \\
\hline \multicolumn{3}{|c|}{$C R O H$ and $F_{S T}$ INDEL windows $(\geq 0.3)$ datasets } \\
\hline ENSGALG00000000242 & EBF2 & early B cell factor 2 \\
\hline ENSGALG00000000667 & EDN2 & endothelin 2 \\
\hline ENSGALG00000004045 & AGAP1 & ArfGAP with GTPase domain, ankyrin repeat and PH domain 1 \\
\hline ENSGALG00000004116 & TRPM8 & transient receptor potential cation channel subfamily $\mathrm{M}$ member 8 \\
\hline ENSGALG00000007555 & CCND1 & cyclin D1 \\
\hline ENSGALG00000007556 & LTO1 & LTO1, ABCE1 maturation factor \\
\hline ENSGALG00000008163 & PSME4 & proteasome activator subunit 4 \\
\hline ENSGALG00000015402 & C3orf38 & chromosome 3 open reading frame 38 \\
\hline ENSGALG00000015403 & EPHA3 & EPH receptor $\mathrm{A} 3$ \\
\hline ENSGALG00000016518 & PHKA2 & phosphorylase kinase regulatory subunit alpha \\
\hline ENSGALG00000016522 & PPEF1 & protein phosphatase with EF-hand domain 1 \\
\hline ENSGALG00000016529 & CDKL5 & cyclin dependent kinase like 5 \\
\hline ENSGALG00000022866 & ZNF654 & zinc finger protein 654 \\
\hline ENSGALG00000025789 & gga-mir-6614 & gga-mir-6614 \\
\hline ENSGALG00000027632 & ACYP2 & acylphosphatase 2 \\
\hline ENSGALG00000027960 & GRPR & gastrin releasing peptide receptor \\
\hline ENSGALG00000028376 & FGF19 & fibroblast growth factor 19 \\
\hline ENSGALG00000034516 & SHISAG & shisa family member 6 \\
\hline ENSGALG00000035116 & STAG1 & stromal antigen 1 \\
\hline ENSGALG00000035906 & YTHDC1 & YTH domain containing 1 \\
\hline ENSGALG00000036810 & novel gene & -- \\
\hline ENSGALG00000036938 & RALYL & RALY RNA binding protein like \\
\hline ENSGALG00000038730 & GIGYF2 & GRB10 interacting GYF protein 2 \\
\hline ENSGALG00000039102 & TOX & thymocyte selection associated high mobility \\
\hline
\end{tabular}


Table 4 Genes annotated commonly between selection signatures of two or more datasets (Continued)

\begin{tabular}{lll}
\hline Gene ID & Gene name & Description \\
\hline ENSGALG00000040322 & novel gene & -- \\
CROH and FST SNP and INDEL windows ( 20.3$)$ & datasets & \\
ENSGALG00000000242 & EBF2 & early B cell factor 2 \\
ENSGALG00000004045 & AGAP1 & ArfGAP with GTPase domain, ankyrin repeat and PH domain 1 \\
ENSGALG00000004116 & TRPM8 & transient receptor potential cation channel subfamily M member 8 \\
ENSGALG00000007555 & CCND1 & cyclin D1 \\
ENSGALG00000007556 & LTO1 & LTO1, ABCE1 maturation factor \\
ENSGALG000000015402 & C3Orf38 & chromosome 3 open reading frame 38 \\
ENSGALG00000015403 & EPHA3 & EPH receptor A3 \\
ENSGALG000000016518 & PHKA2 & phosphorylase kinase regulatory subunit alpha \\
ENSGALG00000016522 & PPEF1 & protein phosphatase with EF-hand domain 1 \\
ENSGALG00000016529 & CDKL5 & cyclin dependent kinase like 5 \\
ENSGALG00000022866 & ZNF654 & zinc finger protein 654 \\
ENSGALG000000028376 & FGF19 & fibroblast growth factor 19 \\
ENSGALG00000035116 & STAG1 & stromal antigen 1 \\
ENSGALG000000035906 & YTHDC1 & YTH domain containing 1 \\
ENSGALG00000036938 & RALYL & RALY RNA binding protein like \\
ENSGALG000000038730 & GIGYF2 & GRB10 interacting GYF protein 2 \\
\hline
\end{tabular}

evolution of the phenotype of TT line. In this sense, genes involved with traits of economic interest were identified in these regions. The genes IGFB2, TGFB2, HOXD9, HOXD10, POMC SPP1, SPP2, and IGF1 were some of the genes annotated in the candidate selection signatures of TT line and that were previously found in other selection signatures and associated with traits such as growth, body weight and composition, abdominal fat, organogenesis and feed intake and consumption [22, 50, 53-66]. Furthermore, we identified a group of genes annotated in the selection signatures that are involved with structural constituents, cell differentiation, and development of muscle tissue: ACTC1, AKAP6, ATP2A2, KCNMA1, MYO1B, MYO1C, MYO1E, MYO1F, MYO6, MYO7A, MYO10, MYO16, TPM4, VCL, and V1PR1 [22, 67]. Selection signatures identified in our analysis also indicate regions involved in lipid metabolism and adipose tissue development, encompassing the $A D C Y 2$, AKAP6, APOB, ATPR2, IGFBP2, PLA2R1, PPARG, SCARB1 and ZNF423 genes [22, 68-77].

Chickens raised in production systems are under several stressful conditions that can affect performance and

Table 5 MeSH enrichment analysis of genes annotated in candidate selection signatures

\begin{tabular}{|c|c|c|c|c|}
\hline MeSH term (MeSH ID) & Gene count & $P$-value & $\mathrm{BH}^{\mathrm{a}}$ & Dataset $^{\mathrm{b}}$ \\
\hline Matrilin Proteins (D064235) & 3 & 0.00008523 & 0.01605961 & $\mathrm{a}$ \\
\hline Muscle, Skeletal (D018482) & 9 & 0.00037904 & 0.04927546 & a \\
\hline Salmonella Infections, Animal (D012481) & 2 & 0.02170325 & 0.02893767 & $b$ \\
\hline Adipose Tissue (D000273) & 9 & 0.00246916 & 0.0157409 & c \\
\hline \multirow[t]{2}{*}{ Cystatins (D015891) } & 2 & 0.00018075 & 0.01590614 & $d$ \\
\hline & 2 & 0.00019528 & 0.02089512 & e \\
\hline Tyrosine (D014443) & 3 & 0.00085140 & 0.03746136 & $d$ \\
\hline \multirow[t]{2}{*}{ Pregnancy in Diabetics (D011254) } & 1 & 0.00703107 & 0.03515533 & $d$ \\
\hline & 1 & 0.00730629 & 0.03653145 & e \\
\hline \multirow[t]{2}{*}{ Hyperglycemia (D006943) } & 1 & 0.01748688 & 0.04066230 & $d$ \\
\hline & 1 & 0.01816762 & 0.04223941 & e \\
\hline
\end{tabular}

Benjamini \& Hochberg procedure for controlling false discovery rate (FDR) [40]

${ }^{b}$ Analysis considering dataset of: (a) 232 genes annotated in $\mathrm{CROH}$ of pools shared between at least 12 animals of both generations; (b) 71 genes annotated in CROH of pools shared exclusively between 7th animals; (c) 1318 genes annotated in CROH of pools shared between at least four 16th animals more than 7th's; (d) 56 genes annotated in $\mathrm{F}_{\mathrm{ST}}$ windows of SNP data (FST $\geq 0.3$ ); and (e) 60 genes annotated in FST windows of INDEL data (FST $\geq 0.3$ ) 


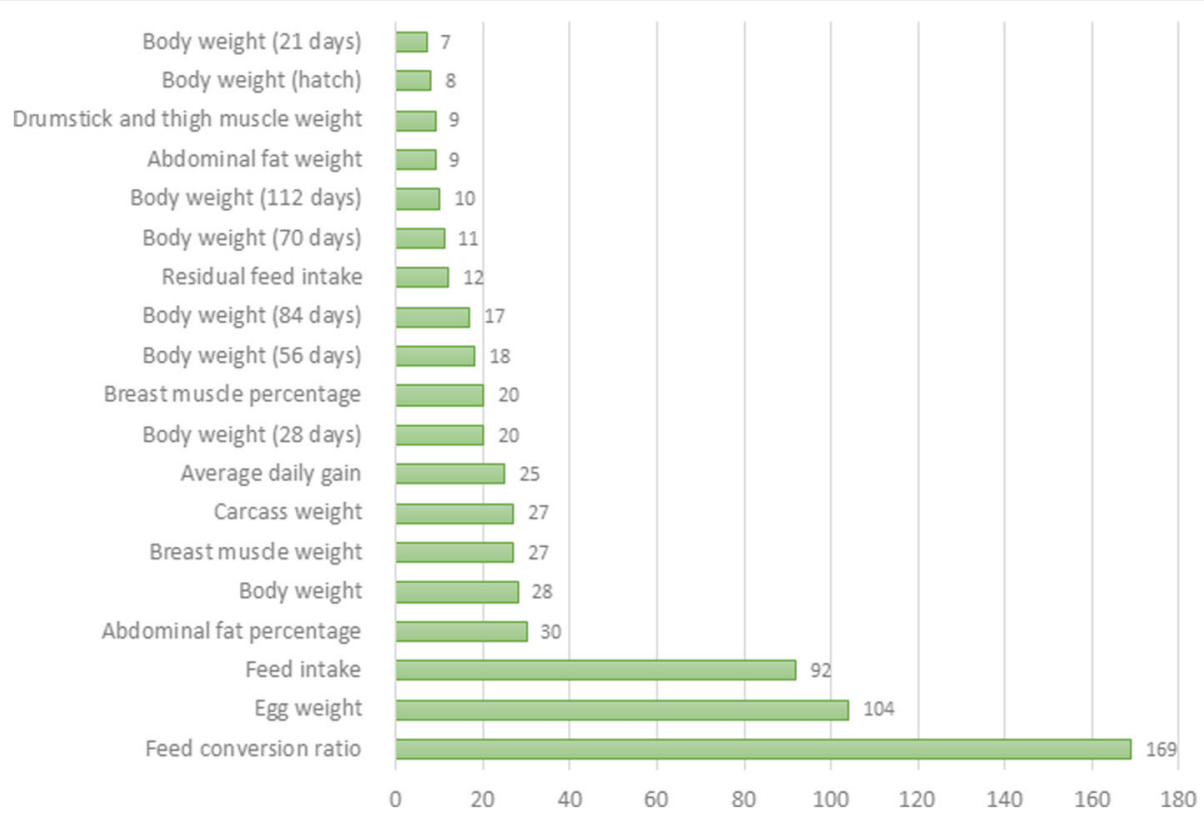

Fig. 7 Manhattan plot of genome wide distribution of $\mathrm{F}_{S T}$ windows for INDEL dataset. Red line represents threshold of 0.3, windows above this value were considered candidate selection signatures

the immune system of these animals [78, 79]. Stress challenged animals respond by changing their response behavior, metabolic rates, and functioning of cardiovascular and immune systems [78]. Thus, a selective pressure over genomic regions controlling responses to stressor conditions may occur, and the selection signatures identified with the $\mathrm{ROH}$ analysis shows a class of genes involved in these aspects: $A C E, B A G 1, C A C N A 1 C$, ELP2, HSPA8, MOCOS, MRTO4, MYH9, NSUN2, PAX5, $P Q L C 2$ and TRPM8 [16, 17, 80, 81].

Changes in $\mathrm{TT}$ line across the generations

Enrichment analysis using $\mathrm{MeSH}$ was performed in order to provide a better integrated view of the changes

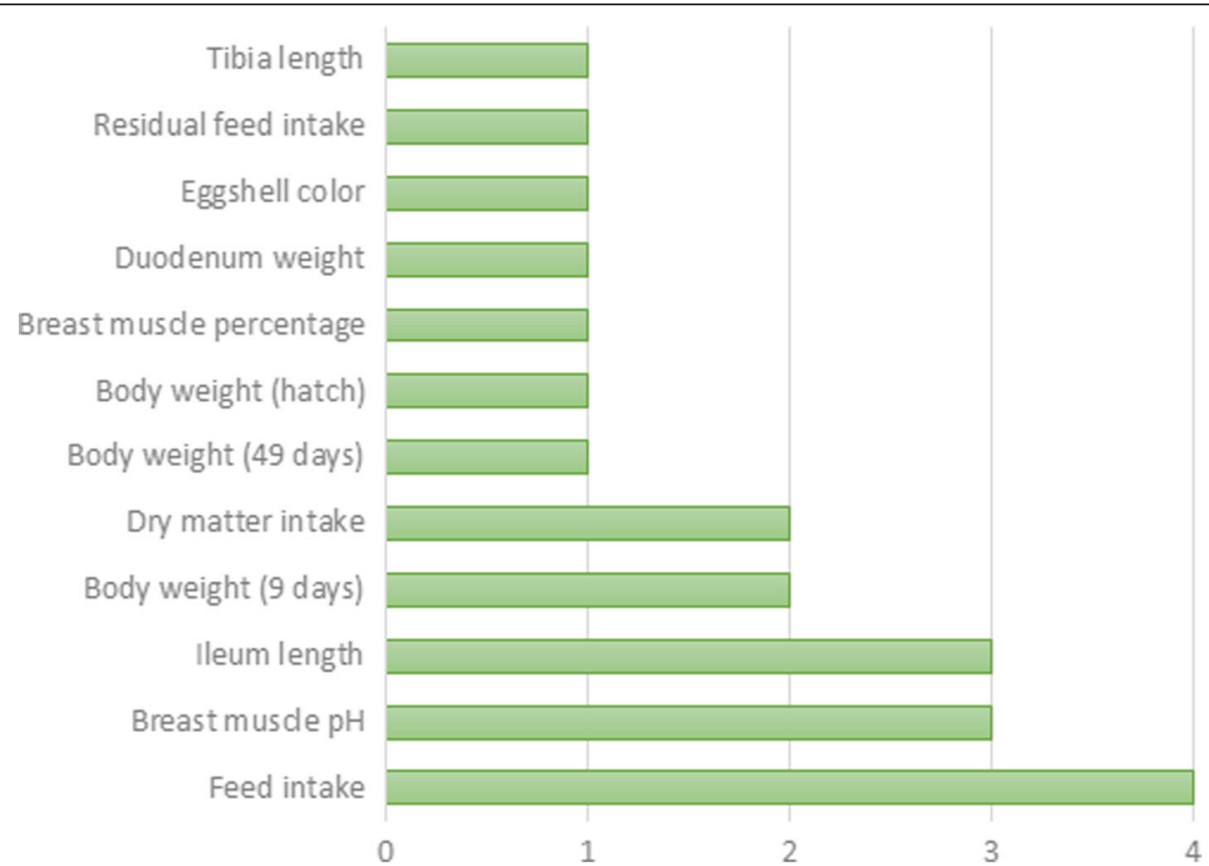

Fig. 8 Manhattan plot of genome wide distribution of $F_{S T}$ windows for INDEL dataset. Red line represents threshold of 0.3, windows above this value were considered candidate selection signatures 


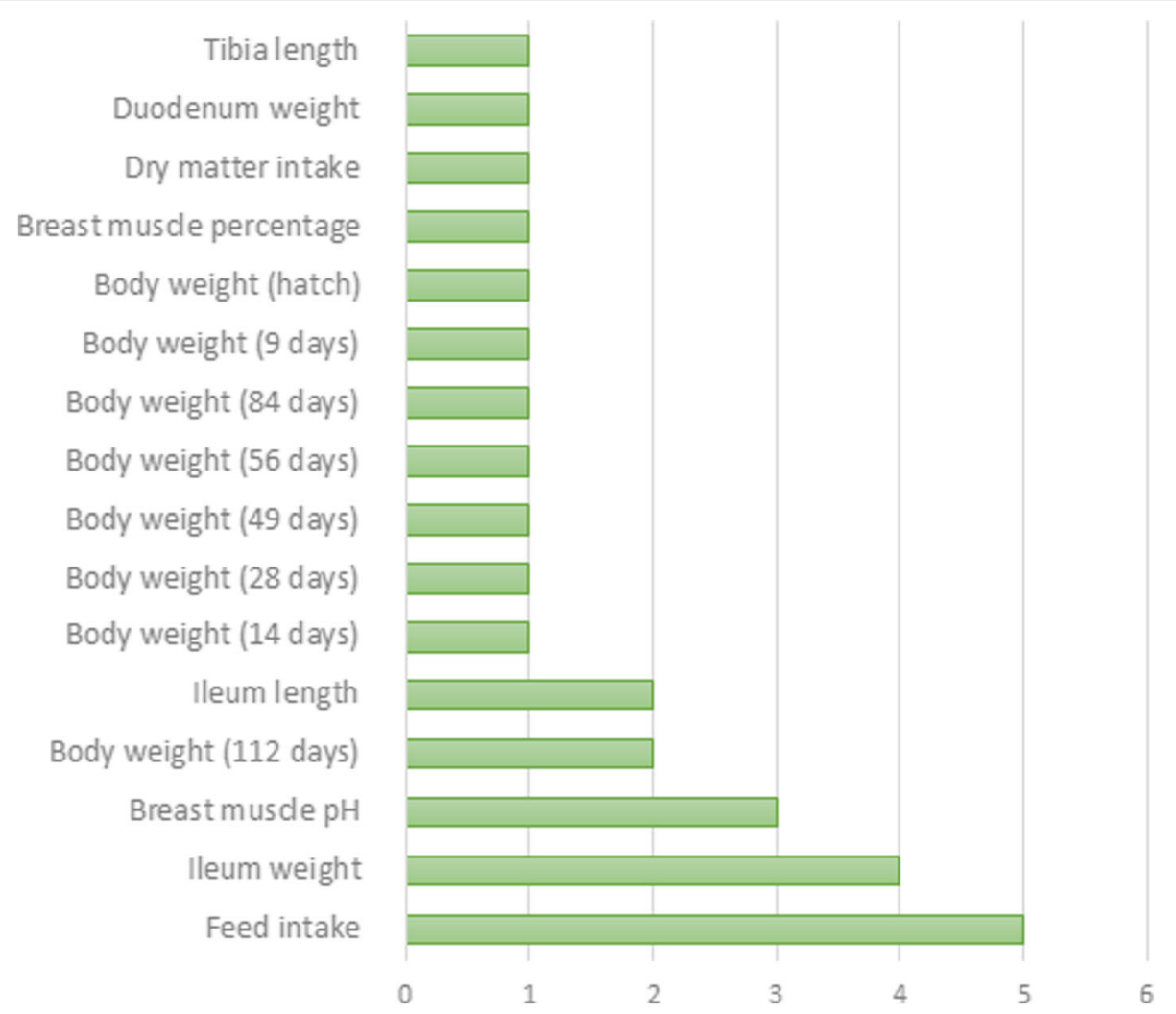

Fig. 9 Manhattan plot of genome wide distribution of $\mathrm{F}_{S T}$ windows for INDEL dataset. Red line represents threshold of 0.3, windows above this value were considered candidate selection signature

that occurred. [82]. Adipose tissue was in overrepresentation among the genes of these regions, what is expected since selection for growth in broilers, could lead to elevated fat deposition [83]. In addition, overlaps of $\mathrm{cROH}$ regions with QTL associated with fat deposition in TT Reference population support that regions affecting these traits were indirectly selected across generations in TT line. Hyperglycemia was also overrepresented and it is possibly a consequence of fat deposition in these animals. The excess of adipose tissue in chickens may lead to a condition similar to the early stage of type 2 diabetes in humans, manifesting hyperglycemia and exogenous insulin resistance $[84,85]$. Another overrepresentation was 'pregnancy in diabetics', and, as it is known, pregnancy is not a biological mechanism of birds. However, Nadaf et al. [83] discuss that some QTL associated with chicken fatness have genes playing a role in obesity and diabetes in humans, and since MeSH is a tool that comprises animals in general, this association may have be done due to genes with similar functions.

Cystatins was among genes annotated in regions that underwent allele frequency changes during the 7th and 16th generations. Cystatin is a superfamily of reversible competitive inhibitors of cysteine proteases such as calpains, cathepsins, and ficins, and the cystatin system have important roles in protein turnover, antigen presentation and disease immunity [86, 87]. As well, tyrosine was overrepresented among the genes of $\mathrm{F}_{\mathrm{ST}} \mathrm{SNP}$ windows, which is considered a nonessential amino acid in animals [88].

The $\mathrm{ROH}$ analysis also provided information about regions that may indicate selection in a period that precedes the studied generations. In these regions there were overrepresentation of genes involved in skeletal muscle and the matrilin proteins, both important for the growth of chickens. Matrilin is a four-member family of proteins composing extracellular matrix of some tissues as cartilage, a connective tissue. They bind to collagencontaining fiber and other matrix constituents and can form oligomers [89].

Furthermore, the abundant amount of overlaps between $\mathrm{cROH}$ and $\mathrm{F}_{\mathrm{ST}}$ windows and QTL regions associated with traits of economic interest in broilers, such as feed conversion, feed intake, growth, and abdominal fat, enforces the results of candidate selection signatures involved in performance traits. This fact together corroborates that TT line have been selected for growth and muscle deposition for a long period with a possible consequence of increased fat deposition, and for some traits such as proteic turnover and metabolism of tyrosine. 
Table 6 QTLs associated with fat traits in TT Reference Population overlapping with consensus runs of homozygosity (cROH)

\begin{tabular}{|c|c|c|c|}
\hline Trait $(\mathrm{QTL} I \mathrm{ID})^{\mathrm{a}}$ & Chr & QTL position (start-end) ${ }^{\mathrm{b}}$ & CROH position (start - end) \\
\hline \multirow[t]{2}{*}{ ABFW (160520) } & 5 & $38,000,437-38,996-916$ & $38,015,470-38,234,917$ \\
\hline & & & $38,425,606-38,473,340$ \\
\hline \multirow[t]{3}{*}{ ABFW (160521) } & 10 & $7,000,336-7,998,549$ & $6,978,426-7,049,244$ \\
\hline & & & $7,474,909-7,543,996$ \\
\hline & & & $7,931,784-7,932,642$ \\
\hline ABFW (160522) & 13 & $3,002,617-3,998,616$ & $3,572,237-3,641,314$ \\
\hline \multirow[t]{2}{*}{ ABFP (160525) } & 5 & $38,000,437-38,996-916$ & $38,015,470-38,234,917$ \\
\hline & & & $38,425,606-38,473,340$ \\
\hline \multirow[t]{3}{*}{ ABFP (160526) } & 10 & $7,000,336-7,998,549$ & $6,978,426-7,049,244$ \\
\hline & & & $7,474,909-7,543,996$ \\
\hline & & & $7,931,784-7,932,642$ \\
\hline ABFP (160527) & 13 & $3,002,617-3,998,616$ & $3,572,237-3,641,314$ \\
\hline \multirow[t]{2}{*}{ SKINW (160529) } & 15 & $6,000,311-6,999,944$ & $6,175,697-6,362,475$ \\
\hline & & & $6,473,966-6,475,580$ \\
\hline \multirow[t]{3}{*}{ SKINW (160531) } & 24 & $5,000,105-5,999,010$ & $4,720,727-5,060,139$ \\
\hline & & & $5,187,457-5,646,905$ \\
\hline & & & $5,899,715-5,962,715$ \\
\hline SKINP (160534) & 9 & $4,000,836-4,999,336$ & $4,664,760-4,860,555$ \\
\hline \multirow[t]{2}{*}{ SKINP (160530) } & 15 & $6,000,311-6,999,944$ & $6,175,697-6,362,475$ \\
\hline & & & $6,473,966-6,475,580$ \\
\hline
\end{tabular}

ABFW abdominal fat weight, ABFP abdominal fat percentage, SKINW skin weight, SKINP skin percentage

${ }^{\mathrm{a}} \mathrm{QTLID}$ from QTL chicken database

${ }^{\mathrm{b}}$ Positions in the Gallus_gallus-5.0 version of the chicken genome

\section{Conclusion}

Regions under selection pressure in a paternal broiler line were investigated in this study. Using $\mathrm{ROH}$ analysis, we were able to identify regions that were inherited backing to common ancestors since the beginning of the broiler line origin, how these regions were shared between the animals of both generations, and what has changed in the genetic make-up of the TT line by selection between the 7 th and 16th generations. $\mathrm{F}_{\mathrm{ST}}$-based analysis revealed regions that changed between generations. Annotation and enrichment analysis revealed the selection program affected genes and biological processes involved in skeletal muscle, cartilage and adipose tissues development. The investigation of selection signatures provided valuable insights about genes and biological processes involved in performance, adaptation and disease traits.

\section{Additional files}

Additional file 1: A text file with information of the $5721 \mathrm{ROH}$ identified in the analysis with the 28 chickens. Information comprises individual identification (IID), chromosome (CHR), start (POS1) and end (POS2) positions, size (KB), number of SNP in each ROH (NSNP), and density of SNP (DENSITY). (TXT $256 \mathrm{~kb}$ )

Additional file 2: A compressed file of images (TIFF format) of genome wide distribution of runs of homozygosity $(\mathrm{ROH})$ in $T$ population for each chromosome. (RAR $144 \mathrm{~kb}$ )

Additional file 3: A text file with information about pools of overlapping $\mathrm{ROH}$ among the 28 chickens. Information comprises pool identification (POOL), family identification (FID), individual identification (IID), chromosome (CHR), start (BP1) and end (BP2) positions, size (KB), and number of SNP in each $\mathrm{ROH}$ of in the pool. Each pool has $n+2$ lines: the $n$ lines are respective to the $n$ individuals in overlap and the last two represents the union and consensus regions of the overlap. (TXT $776 \mathrm{~kb}$ )

Additional file 4: A text file with information of $F_{S T}$ windows using SNP dataset. Information comprises chromosome (CHR), start (START) and end (END) positions, number of variants (NVAR), and weighted $F_{S T}$ values (FST) for each window. (XLSX $19935 \mathrm{~kb})$

Additional file 5: A text file with information of $F_{S T}$ windows using INDEL dataset. Information comprises chromosome (CHR), start (START) and end (END) positions, number of variants (NVAR), and weighted $F_{S T}$ values (FST) for each window. (TXT $2830 \mathrm{~kb}$ )

Additional file 6: List of the 5681 genes annotated in the 1941 consensus regions of runs of homozygosity (CROH). (TXT $2578 \mathrm{~kb}$ ) Additional file 7: List of the 56 genes annotated in the 178 FST windows ( $\geq 0.3$ ) using SNP dataset. (XLS $5840 \mathrm{~kb}$ )

Additional file 8: List of the 60 genes annotated in the 154 FST windows ( $\geq 0.3$ ) using INDEL dataset. (XLS 79 kb)

Additional file 9: Table S1: Genes annotated commonly between selection signatures of two or more datasets. The datasets were the 1941 
consensus regions of $\mathrm{ROH}(\mathrm{CROH})$, the $\mathrm{F}_{\mathrm{ST}} \mathrm{SNP}$ windows $(>0.3)$, and the $\mathrm{F}_{S T}$ INDEL windows (>0.3). (XLS $83 \mathrm{~kb}$ )

Additional file 10: Table S2: Genes previously associated with traits of interest located in candidate selection signatures. Those located in consensus regions of $\mathrm{ROH}$ presents the number of animals sharing the common region, and those located in $\mathrm{F}_{\mathrm{ST}}$ windows present the respective weighted $\mathrm{F}_{\text {ST }}$ values. (XLSX $394 \mathrm{~kb}$ )

Additional file 11: positional information of overlaps between QTL from the QTL database with candidate selection signatures of $\mathrm{ROH}$ and FST windows (SNP and INDEL datasets). (DOCX $20 \mathrm{~kb}$ )

Additional file 12: positional information of overlaps between $\mathrm{CROH}$ of animals of the 7th and 16th generations with $\mathrm{ROH}$ of animals of the $\Pi$ Reference Population. (XLSX 1198 kb)

\section{Abbreviations}

ABFP: abdominal fat percentage; ABFW: abdominal fat weight; CEUA: Ethics Committee on Animal Utilization; CONCEA: National Council of Animal Experimentation Control; $\mathrm{CROH}$ : consensus region of runs of homozygosity; EHH: extended haplotype homozygosity; FDR: false discovery rate; $\mathrm{F}_{\mathrm{ROH}}$ : inbreeding coefficient based on runs of homozygosity; $\mathrm{F}_{\mathrm{ST}}$ : fixation index; IBD: identical-by-descent; IBS: identical-by-state; iHS: integrated haplotype score; INDEL: insertions and deletions; $\mathrm{N}_{\mathrm{e}}$ : effective population size; QTL: quantitative trait loci; ROH: runs of homozygosity; SKINP: skin percentage; SKINW: skin weight; SNP: single nucleotide polymorphism; UCSC: University of California, Santa Cruz; UROH: union region of runs of homozygosity; WGS: whole genome sequencing

\section{Acknowledgments}

Not applicable.

\section{Authors' contributions}

OACA, GCMM, FMR, CB and LLC conceived the idea of this research and participated in the experimental design. OACA and GCMM performed data analyses. OACA drafted the manuscript. OACA, GCMM, FMR, CB, LLC, MCL, AMGI, JOP, and FJN collaborated with interpretation, discussion and writing of the manuscript. AMGI, JOP, MCL, and LLC provided the experimental environment and data analysis support. All authors have read and approved the final manuscript.

\section{Funding}

This study was financed by the Brazilian Agricultural Research Corporation Embrapa (project number 01.11.07.002.04.02), by the thematic project (2014/ 08704-0) from São Paulo Research Foundation (FAPESP) and by the Coordenação de Aperfeiçoamento de Pessoal de Nível Superior - Brasil (CAPES) - Finance Code 001. The National Council of Scientific and Technological Development (CNPq) grant number 481755/2007-1 from the Brazilian Government funded the TT Reference Population development. Almeida received a fellowship from CAPES, Finance Code 001. Moreira received fellowships from FAPESP, grants 14/21380-9 (in cooperation agreement with (APES), and 16/00569-1 as well, fellowship from CNPq, Brazil (153113/2018-9). Coutinho and Ledur are recipients of productivity fellowship from CNPq. The authors thank CAPES, CNPq, and FAPESP for the financial support. The foment agencies provided financial support to generate the data, however, they do not participate on the design of the study, sample collection, analysis, data interpretation and in writing the manuscript.

\section{Availability of data and materials}

All data generated from the analyses of this work are public and included in this article in the main manuscript or as additional files. All the SNPs utilized were submitted to European Variation Archive (EVA) - EMBL-EBI, accession PRJEB25004 and to dbSNP (NCBI) with the submitter handle "LBA_ESALQ". Additional datasets and scripts used in the analyses are available from the corresponding author under reasonable request.

\section{Ethics approval and consent to participate}

This study followed experimental protocols pertinent to animal experimentation with the approval of the Embrapa Swine and Poultry Ethics Committee on Animal Utilization (CEUA) in Concordia, Santa Catarina State,
Brazil, on resolution number 011/2010. It followed the rules of National Council of Animal Experimentation Control (CONCEA) in accordance with international guidelines to guarantee animal welfare.

\section{Consent for publication}

Not applicable.

\section{Competing interests}

The authors declare that they have no competing interests.

\section{Author details}

'University of São Paulo (USP) / Luiz de Queiroz College of Agriculture (ESALQ), Piracicaba, São Paulo, Brazil. ${ }^{2}$ Universidade Federal de Uberlândia (UFU), Uberlândia, Minas Gerais, Brazil. ${ }^{3}$ Noble Research Institute, Ardmore, OK, USA. ${ }^{4}$ Embrapa Suínos e Aves, Concórdia, Santa Catarina, Brazil.

Received: 19 December 2018 Accepted: 20 May 2019

Published online: 03 June 2019

\section{References}

1. Keller SR, Taylor DR. History, chance and adaptation during biological invasion: separating stochastic phenotypic evolution from response to selection. Ecol Lett. 2008;11:852-66.

2. Ceballos FC, Joshi PK, Clark DW, Ramsay M, Wilson JF. Runs of homozygosity: windows into population history and trait architecture. Nat Rev Genet Nature Publishing Group. 2018:19:220-34.

3. Al-Nasser A, Al-Khalaifa H, Al-Saffar A, Khalil F, Al-Bahouh M, Ragheb G, et al. Overview of chicken taxonomy and domestication. Worlds Poult Sci J. 2007; 63:285-300.

4. Sabeti PCC, Reich DEE, Higgins JMM, Levine HZPZP, Richter DJJ, Schaffner SFF, et al. Detecting recent positive selection in the human genome from haplotype structure. Nature. 2002;419:832-7.

5. Voight BF, Kudaravalli S, Wen X, Pritchard JK. A map of recent positive selection in the human genome. PLoS Biol. 2006;4:0446-58.

6. Lewontin RC, Krakauer J. Distribution of gene frequency as a test of the theory of the selective neutrality of polymorphisms. Genetics. 1973;74:175-95.

7. Christofidou P, Nelson CP, Nikpay M, Qu L, Li M, Loley C, et al. Runs of homozygosity: association with coronary artery disease and gene expression in monocytes and macrophages. Am J Hum Genet. 2015;97:228-37.

8. Lencz T, Lambert C, DeRosse P, Burdick KE, Morgan TV, Kane JM, et al. Runs of homozygosity reveal highly penetrant recessive loci in schizophrenia. Proc Natl Acad Sci. 2007;104:19942-7.

9. Orloff MS, Zhang L, Bebek G, Eng C. Integrative genomic analysis reveals extended germline homozygosity with lung cancer risk in the PLCO cohort. PLoS One. 2012;7.

10. Pemberton TJ, Absher D, Feldman MW, Myers RM, Rosenberg NA, Li JZ. Genomic patterns of homozygosity in worldwide human populations. Am J Hum Genet. 2012;91:275-92.

11. Lashmar SF, Visser C, van Marle-Köster E, Muchadeyi FC. Genomic diversity and autozygosity within the SA Drakensberger beef cattle breed. Livest Sc Elsevier BV. 2018;212:111-9.

12. Purfield DC, Berry DP, McParland S, Bradley DG. Runs of homozygosity and population history in cattle. BMC Genet. 2012;13.

13. Szmatoła T, Gurgul A, Ropka-Molik K, Jasielczuk I, Zabek T, BugnoPoniewierska M. Characteristics of runs of homozygosity in selected cattle breeds maintained in Poland. Livest Sci. 2016;188:72-80.

14. Zhao F, McParland S, Kearney F, Du L, Berry DP. Detection of selection signatures in dairy and beef cattle using high-density genomic information. Genet Sel Evol Genetics Selection Evolution. 2015;47:1-12.

15. Bosse M, Megens HJ, Madsen O, Paudel Y, Frantz LAF, Schook LB, et al. Regions of homozygosity in the porcine genome: consequence of demography and the recombination landscape. PLoS Genet. 2012;8.

16. Fleming DS, Koltes JE, Markey AD, Schmidt CJ, Ashwell CM, Rothschild MF, et al. Genomic analysis of Ugandan and Rwandan chicken ecotypes using a 600 k genotyping array. BMC Genomics BMC Genomics. 2016;17:1-16.

17. Marchesi JAP, Buzanskas ME, Cantão ME, Ibelli AMG, Peixoto JO, Joaquim LB, et al. Relationship of runs of homozygosity with adaptive and production traits in a paternal broiler line. Animal [internet]. 2017 [cited 2018 mar 24];19. Available from: http://www.ncbi.nlm.nih.gov/pubmed/29065939

18. Mastrangelo S, Tolone M, Sardina MT, Sottile G, Sutera AM, Di Gerlando R, et al. Genome-wide scan for runs of homozygosity identifies potential 
candidate genes associated with local adaptation in Valle del Belice sheep Genet Sel Evol BioMed Central. 2017:49:1-10.

19. Wright S. The genetical structure of populations. Ann Eugenics. 1951;15:323-54.

20. Weir BS. Estimating F-statistics : a historical view; 2015. p. 79.

21. Lillie M, Sheng ZY, Honaker CF, Andersson L, Siegel PB, Carlborg O. Genomic signatures of 60 years of bidirectional selection for 8-week body weight in chickens. Poult Sci. 2018;97:781-90.

22. Boschiero C, Moreira GCM, Gheyas AA, Godoy TF, Gasparin G, Mariani PDSC, et al. Genome-wide characterization of genetic variants and putative regions under selection in meat and egg-type chicken lines. BMC Genomics [Internet]. 2018; [cited 2018 Mar 19];19:83. Available from: http://www.ncbi. nlm.nih.gov/pubmed/29370772.

23. Venturini GC, Stafuzza NB, Cardoso DF, Baldi F, Ledur MC, Peixoto JO, et al. Association between ACTA1 candidate gene and performance, organs and carcass traits in broilers. Poult Sci. 2015;94:2863-9.

24. Nunes BDN, Ramos SB, Savegnago RP, Ledur MC, Nones K, Klein CH, et al. Genetic parameters for body weight, carcass chemical composition and yield in a broiler-layer cross developed for QTL mapping. Genet Mol Biol [Internet] 2011;34:429-34. Available from: http://www.pubmedcentral.nih. gov/articlerender.fcgi?artid=3168183\&tool=pmcentrez\&rendertype=abstract

25. Langmead B, Salzberg SL. Fast gapped-read alignment with bowtie 2. Nat Methods [Internet] 2012 [cited 2013 Sep 17];9:357-9. Available from: http:// www.pubmedcentral.nih.gov/articlerender.fcgi?artid=3322381\&tool= pmcentrez\&rendertype $=$ abstract

26. Moreira GCM, Godoy TF, Boschiero C, Gheyas A, Gasparin G, Andrade SCS, et al. Variant discovery in a QTL region on chromosome 3 associated with fatness in chickens. Anim Genet [Internet]. 2015 [cited 2018 May 5];46:1417. Available from: http://www.ncbi.nlm.nih.gov/pubmed/25643900

27. Purcell S, Neale B, Todd-Brown K, Thomas L, Ferreira MAR, Bender D, et al. PLINK: A Tool Set for Whole-Genome Association and Population-Based Linkage Analyses. Am. J. Hum. Genet. [Internet]. 2007 [cited 2018 Mar 25];81: 559-75. Available from: http://www.ncbi.nlm.nih.gov/pubmed/17701901

28. Purcell S. PLINK 1.9. p. https://www.cog-genomics.org/plink2.

29. Ceballos FC, Hazelhurst S, Ramsay M. Assessing runs of homozygosity: a comparison of SNP Array and whole genome sequence low coverage data. BMC Genomics BMC Genomics. 2018;19:1-12.

30. Zhang Q, Guldbrandtsen B, Bosse M, Lund MS, Sahana G. Runs of homozygosity and distribution of functional variants in the cattle genome. BMC Genomics BMC Genomics. 2015;16:1-16.

31. Peripolli E, Stafuzza NB, Munari DP, Lima ALF, Irgang R, Machado MA, et al. Assessment of runs of homozygosity islands and estimates of genomic inbreeding in Gyr (Bos indicus) dairy cattle. BMC Genomics BMC Genomics. 2018;19:1-13.

32. McQuillan $\mathrm{R}$, Leutenegger AL, Abdel-Rahman R, Franklin CS, Pericic M, Barac-Lauc L, et al. Runs of homozygosity in European populations. Am J Hum Genet. 2008:83:359-72.

33. Weir BS, Cockerham CC. Estimating F-Statistics for the Analysis of Population Structure. Evolution (N. Y). [Internet]. Society for the Study of Evolution; 1984 [cited 2017 Nov 7]; 38:1358. Available from: http://www.jstor.org/ stable/2408641? origin $=$ crossref

34. Danecek P, Auton A, Abecasis G, Albers CA, Banks E, DePristo MA, et al. The variant call format and VCFtools. Bioinformatics. 2011;27:2156-8.

35. Quinlan AR, Hall IM. BEDTools: a flexible suite of utilities for comparing genomic features. Bioinformatics. 2010;26:841-2.

36. Zerbino DR, Achuthan P, Akanni W, Amode MR, Barrell D, Bhai J, et al. Ensembl 2018. Nucleic Acids Res. 2018;46:D754-61.

37. Yu G. Using meshes for MeSH term enrichment and semantic analyses. Bioinformatics. 2018;34:3766-7.

38. Morota G. R package for MeSH enrichment analysis - GitHub. https://github. com/morota/meshr. 2014.

39. Team RDC. R: a language and environment for statistical computing. 2008. p. https://www.R-project.org.

40. Benjamini Y, Hochberg Y. Controlling the false discovery rate: a practical and powerful approach to multiple testing [internet]. J. R. Stat. Soc. Ser. B. WileyRoyal statistical society; 1995 [cited 2018 may 10]. p. 289-300. Available from: https://www.jstor.org/stable/2346101.

41. Chicken QTL database (release 37). 2018.

42. Moreira GCM, Boschiero C, Cesar ASM, Reecy JM, Godoy TF, Trevisoli PA, et al. A genome-wide association study reveals novel genomic regions and positional candidate genes for fat deposition in broiler chickens. BMC Genomics [Internet]. BioMed Central; 2018 [cited 2018 Jun 7];19:374. Available from: http://www.ncbi.nlm.nih.gov/pubmed/29783939
43. Howrigan DP, Simonson MA, Keller MC. Detecting autozygosity through runs of homozygosity: a comparison of three autozygosity detection algorithms. BMC Genomics. 2011;12.

44. Purfield DC, Mcparland S, Wall E, Berry DP. The distribution of runs of homozygosity and selection signatures in six commercial meat sheep breeds. PLoS One. 2017;12:1-23.

45. Kardos M, Luikart G, Bunch R, Dewey S, Edwards W, Mcwilliam S, et al. Whole-genome resequencing uncovers molecular signatures of natural and sexual selection in wild bighorn sheep. Mol Ecol. 2015;24:5616-32.

46. Farias FHG, Tomlinson C, Labuda J, Perez-Camargo G, Middleton R, Warren WC. The practical use of genome sequencing data in the management of a feline colony pedigree. BMC Vet Res BMC Veterinary Research. 2017;13:1-9.

47. Wright S. Evolution in Mendelian Populations. Genetics. 1931;16:97-159.

48. Nei M, Maruyama T, Chakraborty R. The bottleneck effect and genetic variability in populations. Evolution (N Y). 1975;29:1-10.

49. Ma Y, Wei J, Zhang Q, Chen L, Wang J, Liu J, et al. A genome scan for selection signatures in pigs. PLoS One. 2015;10:1-18.

50. Gholami M, Erbe M, Gärke C, Preisinger R, Weigend A, Weigend S, et al. Population genomic analyses based on 1 million SNPs in commercial egg layers. PLoS One. 2014;9.

51. Willing EM, Dreyer C, van Oosterhout C. Estimates of genetic differentiation measured by fst do not necessarily require large sample sizes when using many snp markers. PLoS One. 2012;7:1-7.

52. Holsinger KE, Weir BS. Genetics in geographically structured populations: defining, estimating and interpreting FST. Nat Rev Genet. 2009;10:639-50.

53. Bai $Y$, Sun G, Kang X, Han R, Tian Y, Li H, et al. Polymorphisms of the proopiomelanocortin and agouti-related protein genes and their association with chicken production traits. Mol Biol Rep. 2012;39:7533-9.

54. Bennett AK, Hester PY, Spurlock DEM. Polymorphisms in vitamin D receptor, osteopontin, insulin-like growth factor 1 and insulin, and their associations with bone, egg and growth traits in a layer - broiler cross in chickens. Anim Genet. 2006:37:283-6.

55. Bhattacharya TK, Chatterjee RN, Dushyanth K, Paswan C, Shukla R, Shanmugam M. Polymorphism and expression of insulin-like growth factor 1 (IGF1) gene and its association with growth traits in chicken. Br Poult Sci. 2015;56:398-407.

56. Bian LH, Wang SZ, Wang QG, Zhang S, Wang YX, Li H. Variation at the insulin-like growth factor 1 gene and its association with body weight traits in the chicken. J Anim Breed Genet. 2008;125:265-70.

57. Zhou H, Mitchell AD, McMurtry JP, Ashwell CM, Lamont SJ. Insulin-like growth factor-I gene polymorphism associations with growth, body composition, skeleton integrity, and metabolic traits in chickens. Poult Sci. 2005;84:212-9.

58. Agarwal SK, Cogburn LA, Burnside J. Comparison of gene expression in normal and growth hormone receptor-deficient dwarf chickens reveals a novel growth hormone regulated gene. Biochem Biophys Res Commun. 1995;206:153-60.

59. Li ZH, Li H, Zhang H, Wang SZ, Wang QG, Wang YX. Identification of a single nucleotide polymorphism of the insulin-like growth factor binding protein 2 gene and its association with growth and body composition traits in the chicken. J Anim Sci. 2006;84:2902-6.

60. Leng L, Wang S, Li Z, Wang Q, Li H. A polymorphism in the 3'-flanking region of insulin-like growth factor binding protein 2 gene associated with abdominal fat in chickens. Poult Sci. 2009;88:938-42.

61. Yamagishi $T$, Ando $K$, Nakamura $H$, Nakajima $Y$. Expression of the Tgf $\beta 2$ gene during Chick embryogenesis. Anat Rec. 2012;295:257-67.

62. Darzi Niarami M, Masoudi AA, Vaez Torshizi R. Association of Single Nucleotide Polymorphism of GHSR and TGFB2 genes with growth and body composition traits in sire and dam lines of a broiler chicken. Anim Biotechnol. 2014;25:13-22.

63. Tang $S$, Ou J, Sun D, Zhang $Y, X u$ G, Zhang $Y$. A novel 62-bp indel mutation in the promoter region of transforming growth factor-beta 2 (TGFB2) gene is associated with body weight in chickens. Anim Genet. 2011;42:108-12.

64. Tickle $\mathrm{C}$. The contribution of chicken embryology to the understanding of vertebrate limb development. Mech Dev. 2004;121:1019-29.

65. Izpisúa-Belmonte JC, Tickle C, Dollé P, Wolpert L, Duboule D. Expression of the homeobox Hox-4 genes and the specification of position in chick wing development. Nature. 1991;350:585-9.

66. Wardlaw SL. Obesity as a neuroendocrine disease: lessons to be learned from proopiomelanocortin and melanocortin receptor mutations in mice and men. J Clin Endocrinol Metab. 2001;86:1442-6. 
67. Sellers JR. Myosins: a diverse superfamily. Biochim Biophys Acta 2000; 200AD; 1496:3-22.

68. Sato K, Abe H, Kono T, Yamazaki M, Nakashima K, Kamada T, et al. Changes in peroxisome proliferator-activated receptor gamma gene expression of chicken abdominal adipose tissue with different age, sex and genotype. Anim Sci J. 2009:80:322-7.

69. Ji B, Ernest B, Gooding JR, Das S, Saxton AM, Simon J, et al. Transcriptomic and metabolomic profiling of chicken adipose tissue in response to insulin neutralization and fasting. BMC Genomics [Internet]. BioMed Central; 2012 [cited 2018 Mar 21];13:441. Available from: http://www.ncbi.nlm.nih.gov/ pubmed/22938590

70. Larkina TA, Sazanova AL, Fomichev KA, Barkova OY, Malewski T, Jaszczak K, et al. HMG1A and PPARG are differently expressed in the liver of fat and lean broilers. J Appl Genet. 2011;52:225-8.

71. Sun YN, Gao Y, Qiao SP, Wang SZ, Duan K, Wang YX, et al. Epigenetic DNA methylation in the promoters of peroxisome proliferator-activated receptor Y in chicken lines divergently selected for fatness. J Anim Sci. 2014;92:48-53.

72. Sato K, Matsushita K, Matsubara Y, Kamada T, Akiba Y. Adipose tissue fat accumulation is reduced by a single intraperitoneal injection of peroxisome proliferator-activated receptor gamma agonist when given to newly hatched chicks. Poult Sci. 2008:87:2281-6.

73. Matsubara Y, Aoki M, Endo T, Sato K. Characterization of the expression profiles of adipogenesis-related factors, ZNF423, KLFs and FGF10, during preadipocyte differentiation and abdominal adipose tissue development in chickens. Comp Biochem Physiol - B Biochem Mol Biol Elsevier Inc. 2013; 165:189-95.

74. Hermier D, Forgez P, Chapman MJ. A density gradient study of the lipoprotein and apolipoprotein distribution in the chicken, Gallus domesticus. Biochim Biophys Acta (BBA)/Lipids Lipid Metab. 1985;836:105-18.

75. Schumaker VN, Phillips ML, Chatterton JE. Apolipoprotein B and low-density lipoprotein structure: implications for biosynthesis of triglyceride-rich lipoproteins. Adv Protein Chem. 1994;45:205-48.

76. Zhang S, Shi H, Li H. Cloning and tissue expression characterization of the chicken APOB gene. Anim Biotechnol. 2007;18:243-50.

77. Zhang S, Li H, Shi H. Single Marker and Haplotype Analysis of the Chicken Apolipoprotein B Gene T123G and D9500D9- Polymorphism Reveals Association with Body Growth and Obesity. Poult. Sci. [Internet]. 2006 [cited 2018 Aug 17];85:178-84. Available from: http://www.ncbi.nlm.nih.gov/ pubmed/16523611

78. Renaudeau D, Collin A, Yahav S, De Basilio V, Gourdine JL, Collier RJ. Adaptation to hot climate and strategies to alleviate heat stress in livestock production. Animal. 2012;6:707-28.

79. Lara LJ, Rostagno MH. Impact of heat stress on poultry production. Animals. 2013:3:356-69.

80. Sun L, Lamont SJ, Cooksey AM, McCarthy F, Tudor CO, Vijay-Shanker K, et al. Transcriptome response to heat stress in a chicken hepatocellular carcinoma cell line. Cell Stress Chaperones. 2015;20:939-50.

81. Chuang HH, Neuhausser WM, Julius D. The super-cooling agent icilin reveals a mechanism of coincidence detection by a temperature-sensitive TRP channel. Neuron. 2004;43:859-69.

82. Morota G, Peñagaricano F, Petersen JL, Ciobanu DC, Tsuyuzaki K, Nikaido I. An application of MeSH enrichment analysis in livestock. Anim Genet [Internet]. 2015 [cited 2018 Aug 20];46:381-7. Available from: http://www. ncbi.nlm.nih.gov/pubmed/26036323

83. Nadaf J, Pitel F, Gilbert H, Duclos MJ, Vignoles F, Beaumont C, et al. QTL for several metabolic traits map to loci controlling growth and body composition in an F2 intercross between high- and low-growth chicken lines. Physiol. Genomics [Internet]. 2009 [cited 2017 Nov 7];38:241-9. Available from: http://www.ncbi.nlm.nih.gov/pubmed/19531576

84. Akiba Y, Chida Y, Takahashi T, Ohtomo Y, Sato K, Takahashi K. Persistent hypoglycemia induced by continuous insulin infusion in broiler chickens. Br Poult Sci. 1999:40:701-5.

85. Renema RA, Rustad ME, Robinson FE. Implications of changes to commercial broiler and broiler breeder body weight targets over the past 30 years. Worlds Poult Sci J. 2007;63:457-72.

86. Ochieng J, Chaudhuri G. Cystatin superfamily. J Health Care Poor Underserved. 2010;21:51-70.

87. Turk V, Stoka V, Turk D. Cystatins: biochemical and structural properties, and medical relevance. Front Biosci. 2008;(13):5406-20.

88. Wu G. Dietary requirements of synthesizable amino acids by animals: a paradigm shift in protein nutrition. J Anim Sci Biotechnol. 2014;5:1-12.
89. Wagener R, Ehlen HWA, Ko YP, Kobbe B, Mann HH, Sengle G, et al. The matrilins - adaptor proteins in the extracellular matrix. FEBS Lett. 2005;579: 3323-9.

\section{Publisher's Note}

Springer Nature remains neutral with regard to jurisdictional claims in published maps and institutional affiliations.
Ready to submit your research? Choose BMC and benefit from:

- fast, convenient online submission

- thorough peer review by experienced researchers in your field

- rapid publication on acceptance

- support for research data, including large and complex data types

- gold Open Access which fosters wider collaboration and increased citations

- maximum visibility for your research: over $100 \mathrm{M}$ website views per year

At BMC, research is always in progress.

Learn more biomedcentral.com/submissions 